\title{
EL MANDATO DEL ARTÍCULO 16.3 DE LA CONSTITUCIÓN A LOS PODERES PÚBLICOS Y ESCUELA: MÁS ALLÁ DE LA INSTRUCCIÓN. REFLEXIONES CON OCASIÓN DE LA LOMLOE
}

Fecha de recepción: 21 de septiembre de 2021

Fecha de aceptación: 7 de octubre de 2021

RESUMEN: Desde la aprobación de la Constitución, en 1978, la «cuestión religiosa» ha sufrido diversos cambios. En el ámbito jurídico, sin duda, lo más relevante ha sido el paso de un Estado totalitario y confesional a uno democrático y de laicidad positiva. Desde la perspectiva social, y precisamente gracias al nuevo modelo de libertad religiosa, España ha pasado de ser un país con una sola fe a uno con pluralidad religiosa. El artículo 16.3 obliga a los poderes públicos a tener en cuenta las creencias de la sociedad española. Procede, ahora, ver en qué medida este mandato afecta a la escuela.

PALABRAS CLAVE: pluralidad religiosa; poderes públicos; libertad religiosa; laicidad positiva; escuela.

\section{The Mandate of Art. 16.3 of Spanish Constitution to the Public Powers and the School. Beyond Instruction}

ABSTRACT: Since the adoption of the Constitution in 1978, the «religious question» has undergone several changes. From a legal perspective, the most relevant de-

Profesora Titular. Departamento Derecho Eclesiástico del Estado.

UNED: arodrizm@gmail.com; ORCID: https://orcid.org/0000-0003-3241-8076 
velopment has undoubtedly been the transition from a totalitarian, confessional state to a democratic state characterized by positive secularism. From a social perspective, and due to the new system of religious freedom, Spain has moved from being a country with a single faith to one based on religious pluralism. Article 16.3 of the Constitution mandates public authorities to take the religious beliefs of Spanish society into account. It is now time to consider to what extent this mandate affects schools.

KEY WORDS: religious pluralism; public authorities; religious freedom; positive secularism; school.

\section{INTRODUCCIÓN}

La religión en la escuela es algo más que la enseñanza de una asignatura. Si bien es cierto que, la doctrina ha venido ocupándose tradicionalmente de esta cuestión ${ }^{1}$, cierto es, también, que la mayoría de las veces se ha olvidado que, desde el punto de vista formativo, la inclusión del factor religioso en el ámbito educativo se podría realizar desde dos perspectivas. En primer lugar, sería posible contar con una perspectiva aconfesional; ésta pasaría por el conocimiento de distintas religiones y, el acercamiento, desde la mera instrucción, a las mismas. Por otro lado, el acercamiento a la religión desde una perspectiva confesional y apologética, destinada y orientada a la formación del fiel, que no del alumno ${ }^{2}$. Los problemas tratados por la Academia parecían centrarse en determinar si la enseñanza de la religión confesional debe insertarse en el currículo como disciplina en condiciones equiparables a las demás; si debe tener el mismo valor que cualquier otra materia o si precisa de una alternativa. Otra cuestión, no menor, la ha constituido el estatuto laboral del profesorado y, fundamentalmente, de si la selección y contratación deben ser asumidas totalmente por las confesiones religiosas, por la autoridad educativa o mantener el sistema mixto vigente en la actualidad ${ }^{3}$. Sobre todas

1 Cf. http://www.ual.es/ canonico/bibliogr/bibsistem/07sist.htm, últ. 17 septiembre 2021.

2 Gustavo Suárez Pertierra. "La enseñanza de la religión en el sistema educativo español”. Laicidad y libertades. Escritos jurídicos 4 (2004): 225-248.

3 Mariano Cubillas Recio. "La enseñanza de la religión en el sistema español y su fundamentación en el derecho de los padres sobre la formación religiosa de sus hijos". Laicidad y Libertades 2 (2002): 157. 
estas cuestiones planean siempre otras de mayor calado, entre ellas, la eliminación de la actual enseñanza religiosa en la escuela y su cabida en un Estado laico. Todos estos asuntos precisan una revisión debido a la trasformación que ha sufrido España en materia de creencias tanto desde la perspectiva jurídica como la sociológica. La metamorfosis en cuestiones de fe hunde sus raíces en el proceso de transición que comienza con la muerte de Francisco Franco. Desde el punto de vista de la ordenación del Estado se pasará de un sistema dictatorial a uno democrático y, desde la perspectiva religiosa, España dejará de ser confesional para beneficiarse de un sistema de laicidad positiva en el que se reconoce la libertad religiosa como derecho fundamental.

Fruto de esa transformación surgirían dudas en materia educativa que la propia Conferencia Episcopal ya advertía en $1976^{4}$. Conservar la presencia de la Iglesia en el mundo escolar, la cabida de la formación religiosa en el ámbito escolar o la existencia de centros educativos pertenecientes a la Iglesia eran, entonces, algunas de las incertidumbres en el proceso constituyente. Sin embargo, creemos que es posible afirmar que esas preocupaciones están a, a nuestro juicio, superadas. En la actualidad, el factor religioso concierne también al sistema educativo en la gestión de la convivencia en las aulas.

Así pues, la fe en la escuela se hace presente de diferentes maneras. La libertad de enseñanza amplía las que ya hemos señalado. Si tomamos prestado el concepto que, de la libertad de enseñanza, nos ofrece la Ley Orgánica del Derecho a la Educación, entendiendo la libertad de enseñanza en un sentido amplio y no restrictivo, veremos que abarca todo el conjunto de libertades y derechos en el terreno de la educación y entenderemos la relación directa con las creencias. Así pues, la libertad de crear centros docentes y de dotarlos de un carácter o proyecto educativo propio; la capacidad de los padres de poder elegir para sus hijos centros docentes distintos de los creados por los poderes públicos, así como la formación religiosa y moral que esté de acuerdo con sus convicciones ${ }^{5}$,

\footnotetext{
4 https://www.conferenciaepiscopal.es/comisiones/educacion-y-cultura/, últ.14 septiembre 2021.

5 «En estos principios debe inspirarse el tratamiento de la libertad de enseñanza, que ha de entenderse en un sentido amplio y no restrictivo, como el concepto que abarca todo el conjunto de libertades y derechos en el terreno de la educación. Incluye, sin duda, la libertad de crear centros docentes y de dotarlos de un carácter o proyecto educativo propio, que se halla recogida y amparada en el Capítulo III del Título I. Incluye,
} 
componen el haz de manifestaciones de la religión en la educación que van más allá de la asignatura.

Las creencias de la sociedad española deben ser tenidas en cuenta por los poderes públicos, así lo manda la Constitución ${ }^{6}$. Cada día más, y sobre todo con la aparición de nuevos grupos religiosos, la fe deja de estar identificada con el ámbito institucional. La escuela es, además del centro transmisor de conocimiento, un lugar de convivencia y aprendizaje más allá del currículo. En ese marco deben coexistir las distintas religiones. Parece que los sistemas de gestión heredados de nuestro pasado confesional y hegemónico no ofrecen respuestas suficientes. Los poderes públicos deben asumir la obligación de garantizar una zona de autonomía para que los individuos puedan ejercer sus derechos en la integración de aspectos de acción positiva por parte del Estado y de esta manera superar los planteamientos, primero institucionalistas y luego personalistas que sólo requieren del poder público una actitud de abstención ${ }^{7}$. No resultaría aventurado decir que «tener en cuenta las creencias de la sociedad española» en el ámbito escolar supone implementar políticas que mejoren la convivencia interreligiosa formando ciudadanos que en el futuro superen de una vez por todas la "cuestión religiosa ${ }^{8}$. Para ello revisaremos

asimismo, la capacidad de los padres de poder elegir para sus hijos centros docentes distintos de los creados por los poderes públicos, así como la formación religiosa y moral que esté de acuerdo con sus convicciones, tal como se recoge en el artículo 4. ${ }^{\circ}$. Pero la libertad de enseñanza se extiende también a los propios profesores, cuya libertad de cátedra está amparada por la Constitución por cuanto constituye principio básico de toda sociedad democrática en el campo de la educación. Y abarca, muy fundamentalmente, a los propios alumnos, respecto de los cuales la protección de la libertad de conciencia constituye un principio irrenunciable que no puede supeditarse a ningún otro». Preámbulo. Ley Orgánica 8/1985, de 3 de julio, reguladora del Derecho a la Educación, BOE, núm. 159, de 4 de julio de 1985, 21015-21022.

6 16.3. «Ninguna confesión tendrá carácter estatal. Los poderes públicos tendrán en cuenta las creencias religiosas de la sociedad española y mantendrán las consiguientes relaciones de cooperación con la Iglesia católica y las demás confesiones». Constitución Española 1978 (CE).

7 Gustavo Suárez Pertierra. "La libertad religiosa, ideológica y de culto". En Derecho eclesiástico del Estado, coordinado por Gustavo Suárez Pertierra, 127-128. Valencia: Tirant lo Blanch, 2016.

8 Permítame el lector utilizar la expresión «cuestión religiosa» generalmente vinculada al periodo de la Segunda República, como un mero guiño. No se trata de identificar ambas situaciones, sino de un juego de palabras con una terminología propia del análisis de las relaciones Iglesia-Estado. 
la importancia de la asignatura de religión confesional ofreciendo una nueva visión de la misma a la vez que plantearemos sugerencias para la asignatura no confesional que plantea la Ley Orgánica 3/2020, de 29 de diciembre, por la que se modifica la Ley Orgánica 2/2006, de 3 de mayo, de Educación (LOMLOE).

\section{LOS CAMBIOS DE LA SOCIEDAD ESPAÑOLA EN MATERIA DE CREENCIAS}

Hemos advertido que los cambios que han tenido lugar en España en el último siglo han sido determinantes a la hora de configurar un sistema educativo en el que la fe de los ciudadanos debe tener reconocimiento y en el que la religión, y, por decir de manera más comprehensiva, las creencias, no puedan ser marginadas en la escuela.

\subsection{Pluralismo Religioso}

El pluralismo religioso existe en España por una razón principal: el derecho español lo posibilita al reconocer la libertad religiosa de los individuos y las comunidades ${ }^{9}$. Pero no es ésta la única razón. El avance imparable de la secularización y los movimientos migratorios han sido dos factores determinantes. Somos conscientes de que no podemos identificar la diversidad religiosa con el fenómeno migratorio, pero obviarlo sería imperdonable ${ }^{10}$. A nadie se le oculta que, a pesar de la irrupción de la COVID y lo que ha supuesto en limitación de movimientos a nivel global, aún hoy hay más de doscientos millones de personas que residen o trabajan fuera de sus lugares de origen ${ }^{11}$.

9 María José Ciáurriz Labiano. "La vigente Ley Orgánica de Libertad Religiosa: Una gran novedad jurídica". En "40 aniversario de la Ley Orgánica de Libertad Religiosa”. Derecho y religión 15 (2020): 251-262.

10 En una muestra clara de esa importancia el trabajo de Oscar Celador Angón. "Libertad de conciencia, integración e inmigración. Lecciones desde el Reino Unido". Cuadernos electrónicos de filosofía del derecho 43 (2020).

11 Gonzalo Fanjul Suárez. "Migraciones internacionales: las consecuencias de gobernar el siglo XXI con políticas del XIX. En ARI 56/2010 - 23/03/2010, Publicaciones del Real Instituto Elcano. 
Los flujos migratorios han supuesto un cambio esencial en las sociedades del siglo XXI, como muy bien señala Celador, éste continúa siendo uno de los retos principales que debemos abordar en el presente siglo ${ }^{12}$. El fenómeno migratorio no ha tenido lugar por primera vez estas últimas décadas. Sin embargo, los desplazamientos han tenido una dimensión sin precedentes y han configurado un mapa cultural complejo en el que conviven individuos de orígenes y tradiciones culturales muy diferentes. Europa, alejada del espíritu de la Paz de Ausburgo, ha visto completamente alterado su panorama religioso. España, otrora emisora de migrantes, ha debido enfrentarse a la quiebra de su tradicional homogeneidad cultural. La pertenencia a una Europa sin fronteras y de libre circulación de los ciudadanos ha obligado a los países que conforman la Unión Europea (UE) a realizar políticas conjuntas en el tema que nos ocupa. España es, además, uno de los países de la UE que más inmigrantes recibe. Desde 2004, a nuestro país llegó uno de cada tres migrantes que pisaban suelo comunitario. Así lo desvela un informe interno de las Naciones Unidas sobre movimientos de población, que destaca que los extranjeros han aumentado en cuatro años más del 304\%, algo sin parangón en las naciones industrializadas ${ }^{13}$.

Las creencias religiosas no son una exclusiva de la inmigración, lo hemos dicho. La religión existe en las distintas sociedades que componen el globo. Sin embargo, es preciso poner de manifiesto la importancia de la fe para los migrantes. Cuando un ser humano encuentra la necesidad de ir de un sitio a otro en busca de una mayor prosperidad pocas cosas puede llevar consigo, una de ellas es su religión. La identificación de distintas civilizaciones con una fe concreta no fue una exclusiva de nuestro país ${ }^{14}$. El migrante viaja unido a sus creencias y, en ocasiones, aumentará su ligamen ya que la religión actúa, en gran medida, como vínculo con su sociedad de origen. Es una realidad que los lugares de culto y reunión se convierten, en la mayoría de las ocasiones, en espacios de socialización para los recién llegados. Allí, además de la celebración religiosa, podrán encontrar a otros individuos en sus circunstancias con quienes relacionarse. Por otra parte, los centros religiosos ofrecen a los inmigrantes recién

12 Oscar Celador Angón. "Libertad de conciencia, integración e inmigración...", o. c., 66 .

13 Estudio presentado el 25 de mayo de 2006 a la División de Población del Departamento de Economía y Asuntos Sociales de la ONU.

14 En Europa después de la Paz de Ausburgo cada reino ostentará la religión de su rey, quedará así establecido el principio: «cuius regio, eius religio». 
llegados un espacio en el que su lengua y sus tradiciones - $\mathrm{O}$ al menos algunas de ellas- no son estigmatizadas, sino que, por el contrario, se encuentran valoradas. Esto crea, muchas veces, una unión especial entre los inmigrantes y la religión. De esta forma, la religión se convierte en una especie de «trinchera identitaria». En algunos casos, probablemente poco frecuentes, pero no por ello menos significativos, se llega a otorgar un valor mayor a la reivindicación identitaria que el sentido religioso en sí mismo ${ }^{15}$.

La Iglesia católica continúa siendo la religión mayoritaria en España y lo es abrumadoramente. Según el Observatorio del Pluralismo religioso en España, del 70,47\% de ciudadanos que se consideran religiosos el 63,19\% se considera católico eso implica que, en España aproximadamente el $89.7 \%$ de los creyentes son católicos ${ }^{16}$. Los porcentajes se reproducen a la hora de hablar de entidades religiosas ${ }^{17}$.

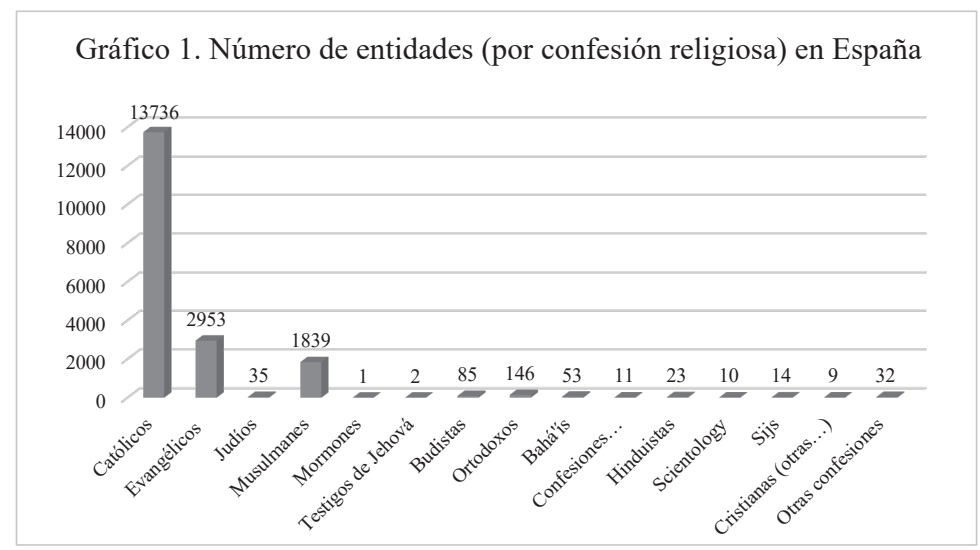

15 Olga Odgers-Ortiz. "Migración, identidad y religión: aproximaciones al estudio del papel de la práctica religiosa en la redefinición identitaria de los migrantes mexicanos". Amerique Latine. Histoire \& Memoire 7 (2003).

16 Datos del Observatorio del pluralismo religioso en España. https://www.observatorioreligion.es/banco-de-datos/1_1_confesion_religiosa_de_la_poblacion_residente_en_espana_en_la_actualidad.html

17 Tomamos como referencia las inscritas en el Registro de Entidades Religiosas (RER). Cuadro utilizado por deferencia de D. Rául Carricondo. Fuente: Elaboración propia a partir de los datos extraídos en la web (Ministerio de la Presidencia, Relaciones con las Cortes y Memoria Democarática, 2021). A las 13736 entidades católicas, hay que sumar las casi 24000 parroquias católicas dependientes de las diferentes diócesis. Éstas no figuran inscritas en el RER puesto que, conforme al acuerdo sobre asuntos jurídicos, sólo son comunicadas cuando son erigidas, y por eso no figuran inscritas en el RER. 
Resulta muy importante señalar que el verdadero cambio en materia de creencias no ha sido el pluralismo, el verdadero cambio lo ha supuesto el incremento de no creyentes o no pertenecientes a ninguna confesión religiosa. ¿Quiere esto decir que la religión debe pasar a un segundo plano? En nuestra opinión no. Las creencias religiosas, como acabamos de ver, tienen una importancia extraordinaria en la sociedad española y, por tanto, tal y como obliga nuestra Carta Magna, han de ser tenidas en cuenta por los poderes públicos.

\subsection{LAICIDAD POSITIVA}

Esta realidad sociológica debe ser atendida por los poderes públicos, lo manda la constitución. «Los poderes públicos tendrán en cuenta las creencias religiosas de la sociedad española». Con esta afirmación la $\mathrm{CE}$ está exigiendo una actitud concreta en la que los diferentes poderes deberán realizar sus funciones considerando el factor religioso. Deben tomar en consideración las creencias sin confundir este reconocimiento social del sentimiento religioso con una confesionalidad sociológica a modo decimonónico. Esta afirmación, bien entendida, lejos de respaldar la confesionalidad sociológica podría permitir arbitrar distintas soluciones a problemas concretos ${ }^{18}$.

En nuestra opinión este mandato del texto constitucional es el que convierte nuestro sistema en un modelo laicidad positiva. Es este mandato, más allá de la cooperación, el que aleja cualquier posibilidad de laicismo mal entendido que pudiera entrar en colisión con las creencias de los ciudadanos. Creemos, además, que debe servir como límite al ejercicio de la cooperación. Esto precisa algunas consideraciones.

Tener en cuenta las creencias de la sociedad no implica abandonar la necesaria neutralidad, recordemos que ésta no implica indiferencia. Por el contrario, este mandato la refuerza. El 16.3 no insta a los poderes públicos a entrar en valoraciones del fenómeno religioso y mucho menos la fe de los ciudadanos. Obliga a la equitatividad, objetividad e independencia del poder político frente al religioso. En definitiva, excluye la posibilidad de que los poderes públicos regulen desde desinterés por el

\footnotetext{
18 Planeamiento y gestión urbanística; cementerios y servicios funerarios; intervención social y alimentación son algunos ejemplos.
} 
sentimiento religioso de los individuos y que tal sentimiento quede relegado al ámbito de lo íntimo ${ }^{19}$.

Esta interpretación es coherente con el resto del texto constitucional y no supone ninguna «filigrana hermenéutica» para concluir que estamos ante un derecho prestacional ${ }^{20}$. Creemos, sin embargo, que es preciso que este apartado del artículo 16.3. encuentre reconocida su importancia y sea analizado por la doctrina de la misma manera que la cooperación, máxime cuando sitúa al ciudadano en el centro del modelo constitucional. Estamos con Ibán cuando sugiere que la libertad supone, ante todo, reconocer al individuo y a su autonomía como el fin último hacia el que debe enderezarse toda actuación del Estado ${ }^{21}$.

Una reflexión similar realiza el Tribunal Constitucional (TC) en su sentencia (STC) 46/2001, de 15 de febrero. El TC incorpora una idea de aconfesionalidad o laicidad positiva que «veda cualquier tipo de confusión entre fines religiosos y estatales» (STC 177/1996). El constituyente consideró el componente religioso perceptible (nótese que no hay una valoración de carácter positivo, tampoco negativo), en la sociedad española y ordena, además, a los poderes públicos mantener «las consiguientes relaciones de cooperación con la Iglesia Católica y las demás confesiones». El tribunal 16.3 matiza la redacción del artículo 16.3 y sugiere que, exige a los poderes públicos una actitud positiva, pero desde una perspectiva que pudiéramos llamar asistencial o prestacional respecto del ejercicio colectivo de la libertad religiosa, no de la religión y tampoco, claro está, de las confesiones religiosas. La cooperación se convierte así en un elemento más que refuerza la idea de laicidad positiva que ya adelantara la obligación de tener en cuenta las creencias.

Ha sido el TC el que ha definido el modelo español como un modelo de laicidad positiva y lo ha conectado con el siguiente apartado del artículo 16.3: la cooperación. El TC transforma de esta manera la forma de

19 «Neutralidad es imparcialidad. Esto no puede interpretarse en el sentido de que las creencias religiosas y las convicciones de los individuos no deban ser tenidas en cuenta por el Estado; por el contrario, son relevantes para la acción pública y, por tanto, imparcialidad frente a las convicciones de los ciudadanos por parte del Estado no quiere decir indiferencia». Gustavo Suárez Pertierra. "La libertad religiosa...", o. c., 128.

20 José Martínez de Pisón. "Poderes públicos y religión. El difícil compromiso con la libertad de conciencia”. REDUR 0 (2002): 94.

21 Iván C. Ibán. Derecho eclesiástico. Madrid: Trotta, 2016, 102. 
entender las relaciones Iglesia-Estado. La solución tomada por el constituyente era deudora de un pasado concordatario que hoy podría carecer de sentido. Sin embargo, resultó razonable, en su momento, tener en cuenta los compromisos adquiridos ${ }^{22}$ y con la nueva realidad jurídica el modelo se amplió a otros sujetos.

Hemos renegado del criterio cuantitativo para evitar cualquier relación entre el modelo de Estado y el reconocimiento de una confesionalidad sociológica. Sin embargo, el artículo 7 de la LOLR ha vinculado el número de creyentes de las confesiones con la posibilidad de mantener acuerdos con el $\mathrm{Estado}^{23}$. Somos conscientes que desde la aprobación del RD 593/2015 ese criterio ha quedado establecido en nuestro derecho. Sin embargo, es un requisito que sólo debe limitarse a hacer efectiva la cooperación con las confesiones religiosas. Ir más allá y configurar un régimen diferente para los creyentes podría implicar que la libertad religiosa de los individuos se hace depender de su adscripción a una confesión más o menos numerosa ${ }^{24}$.

Debemos insistir en que la laicidad positiva se manifiesta fundamentalmente en el mandato constitucional de tener en cuenta las creencias de la sociedad española. Los acuerdos, convenios o cualquiera que sea la fórmula escogida para cumplir con el mandato no es, o no debe ser, lo más relevante.

\section{DESARROLLO ORGÁNICO DEL ARTÍCULO 27 CE Y EL FACTOR RELIGIOSO}

Con la aprobación de la CE en 1978 sabemos que se configura un nuevo orden jurídico sobre dos pilares fundamentales: aconfesionalidad estatal y libertad religiosa. Suárez Pertierra explica con claridad el modelo

${ }^{22}$ Gustavo Suárez Pertierra. "Estado y religión: la calificación del modelo español". Revista catalana de dret public 33 (2006): 15-42.

23 Es un requisito «para las confesiones», no para los ciudadanos.

24 En cualquier caso, somos conscientes de que el criterio cuantitativo ha cobrado especial importancia desde la aprobación del RD 593/ 2015, de 3 de julio. En nuestra opinión con ello se genera un sistema de alguna manera discriminatorio al reservar a unos ciudadanos una protección mayor de la libertad religiosa sólo por pertenecer a confesiones con mayor número de creyentes. 
que se establece en el 78 añadiendo un tercer pilar: la tolerancia ${ }^{25}$. Desde ese momento, el legislador tuvo una difícil tarea por delante en materia educativa: ajustar la tradicional enseñanza religiosa a la nueva realidad jurídica. Era un camino complejo y no exento de conflictividad. De hecho, la enseñanza de la religión se ha convertido en uno de los temas de los más debatidos por la doctrina y la sociedad españolas ${ }^{26}$.

Nuestra norma suprema reconoce el derecho de los padres a educar a los hijos conforme a su ideología, religión o creencias, sin embargo, no queda definido de manera clara en el texto constitucional en qué manera. En estos años de vigencia de la CE no han faltado análisis del precepto, centrados, en muchas ocasiones, en la enseñanza confesional ${ }^{27}$. El TC relacionó de manera temprana la enseñanza religiosa con la libertad de enseñanza, reconocida en el art. 27.1 y la vincula con el tercer apartado del mismo precepto ${ }^{28}$.

25 Gustavo Suárez Pertierra. "La recuperación del modelo constitucional. La cuestión religiosa a los veinticinco años de la Constitución". Laicidad y libertades. Escritos jurídicos 2 (2002): 324.

${ }^{26}$ Cf. http://www.ual.es/ canonico/bibliogr/bibsistem/07sist.htm. La asignatura de religión ha ocupado portadas de los periódicos de mayor tirada nacional. Sirva como ejemplo de la importancia de la cuestión una simple búsqueda en internet. Si en el buscador (en este caso Google) tecleamos «asignatura de religión en España», la búsqueda arroja aproximadamente 1720000 resultados. https://www.google.com/search?q=asignatura+de+religi $\% \mathrm{C} 3 \% \mathrm{~B} 3 \mathrm{n}+\mathrm{en}+\mathrm{espa} \% \mathrm{C} 3 \% \mathrm{~B} 1 \mathrm{a} \& \mathrm{rlz}=1 \mathrm{C} 1 \mathrm{ASUM}$-enES692ES692\&o$\mathrm{q}=$ asignatura+de+religi $\% \mathrm{C} 3 \% \mathrm{~B} 3 \mathrm{n}+\mathrm{en}+\mathrm{espa} \% \mathrm{C} 3 \% \mathrm{~B} 1 \mathrm{a} \& \mathrm{aqs}=$ chrome..69i57j0i512j0i22i30.6887j0j7\&sourceid=chrome\&ie=UTF-8, últ. 8 septiembre 2021.

27 «La enseñanza religiosa en las escuelas públicas, es decir, en las escuelas mantenidas por organismos de derecho público cuenta con una especial importancia. De acuerdo con el artículo 7, párrafo 3 de la GG y conforme a la mayoría de las constituciones regionales y a numerosos tratados entre la Iglesia y el Estado, se trata de una asignatura ordinaria, es decir, una asignatura con la misma posición y tratamiento que el resto. 59 Según el artículo 7, párrafo 3 de la GG, la enseñanza religiosa es más que la mera ciencia de la religión. En la enseñanza religiosa a los alumnos no sólo se les transmiten conocimientos religiosos, sino que se les presenta (no sin elementos de predicación de la fe) la doctrina de una confesión religiosa concreta. La enseñanza religiosa en Alemania es confesional por principio. Eso queda demostrado de manera evidente en el artículo 7, párrafo 3, segunda frase de la GG. A continuación, se añade que la enseñanza religiosa se imparte sin perjuicio del derecho de supervisión del Estado, "de acuerdo con los principios de las comunidades religiosas" ». Stefan Muckel. "El Estado y la Iglesia en Alemania”. Revista catalana de dret públic 33 (2006): 267-293.

28 STC 5/1981, de 13 de febrero. Aunque es importante no confundir este derecho de los padres con el de elegir centro docente, que deriva, sin duda del 27.3. CE. 
También las leyes educativas han ido modificando el tratamiento de lo religioso ${ }^{29}$. Si en un primer momento el objeto principal de la legislación en la cuestión se centraba en la asignatura confesional y en la libertad de enseñanza desde la perspectiva del ideario, poco a poco la religión aparecerá desde otras perspectivas.

En 1980 se aprueba la Ley Orgánica de Estatutos de Centros Escolares (LOECE) que recoge la protección del derecho de libertad religiosa de los alumnos ${ }^{30}$ y consagra, respecto de los centros públicos, la obligación de los centros de respetar las opciones filosóficas y religiosas consustanciales al ejercicio de los padres de los alumnos del centro del derecho reconocido en el artículo 27.3, de la $\mathrm{CE}^{31}$. Por último, refuerza ese mismo derecho enunciando la libertad de enseñanza que permitirá escoger el centro docente que mejor se acomode a esas convicciones ${ }^{32}$.

Apenas cinco años más tarde, la Ley Orgánica del Derecho a la Educación (LODE) consagrará el sistema español como un sistema de carácter

${ }_{29}$ Sin olvidar la enseñanza superior, aquí trataremos de la enseñanza preuniversitaria. María José Ciáurriz Labiano. "La Enseñanza Superior en el Acuerdo sobre Enseñanza y Asuntos Culturas: visión de conjunto”. En Enseñanza superior y religión en el ordenamiento jurídico: actas del VII simposio internacional de derecho concordatario, Trujillo (Cáceres), 7-9 de octubre de 2015, editado por María Dolores Cebriá García, 57-82. Granada: Comares, 2016.

30 Artículo quinto.

Uno. Los padres y tutores tienen el derecho a elegir el tipo de educación que deseen para sus hijos o pupilos y a que éstos reciban, dentro del sistema educativo, la educación y la enseñanza conforme a sus convicciones filosóficas y religiosas, a cuyo efecto podrán escoger el centro docente que mejor se acomode a esas convicciones. [...]. Ley Orgánica 5/1980, de 19 de junio, por la que se regula el Estatuto de Centros Escolares. BOE núm. 154, de 27 de junio de 1980.

31 Artículo veintitrés.

Todas las actividades del centro estarán sometidas a los principios consagrados en la Constitución y respetarán las opciones filosóficas y religiosas inherentes al ejercicio de los padres de los alumnos del centro del derecho reconocido en el artículo veintisiete, tres, de la Constitución. La Administración docente velará, en todo caso, por su cumplimiento. Ley Orgánica 5/1980, de 19 de junio, por la que se regula el Estatuto de Centros Escolares. BOE núm. 154, de 27 de junio de 1980.

32 Artículo treinta y seis.

Los alumnos tendrán los siguientes derechos:

a) A que se respete su conciencia cívica, moral y religiosa, de acuerdo con la Constitución. Ley Orgánica 5/1980, de 19 de junio, por la que se regula el Estatuto de Centros Escolares. BOE núm. 154, de 27 de junio de 1980. 
mixto o dual, con un componente público mayoritario y uno privado de magnitud considerable con lo que consolidará la protección de la libertad de enseñanza en las leyes de educación. Desde el preámbulo se vincula la libertad de enseñanza con el derecho de los padres del, tantas veces citado, artículo 27.3. También el preámbulo enuncia la protección de la libertad de conciencia de los alumnos a la que califica como «un principio irrenunciable» que no puede supeditarse a ningún otro y que queda materializado en el artículo sexto de la ley ${ }^{33}$. Además de la elección de centro docente, el artículo cuarto reitera el derecho de los padres en lo que se puede interpretar como el reconocimiento de una asignatura confesional. Resulta importante subrayar que la actividad educativa de los centros públicos habrá de desarrollarse respetando las convicciones de los padres ${ }^{34}$. Asimismo, se refleja en el texto el principio de no discriminación por razones religiosas ${ }^{35}$.

En 1990 ese principio abrirá el texto la Ley Orgánica General del Sistema Educativo (LOGSE) y, a grandes rasgos, tratando de responder a la nueva realidad autonómica de España. La LOGSE continuará la estela de las leyes anteriores y reconocerá el derecho a crear centros docentes distintos de los públicos; así como el derecho a recibir formación religiosa

\footnotetext{
33 Artículo sexto.

1. Se reconoce a los alumnos los siguientes derechos básicos:

[...]

c) Derecho a que se respete su libertad de conciencia, así como sus convicciones religiosas y morales, de acuerdo con la Constitución. Ley Orgánica 8/1985, de 3 de julio, reguladora del Derecho a la Educación. BOE núm. 159, de 4 de julio de 1985.

34 Artículo dieciocho.

1. Todos los centros públicos desarrollarán sus actividades con sujeción a los principios constitucionales, garantía de neutralidad ideológica y respeto de las opciones religiosas y morales a que hace referencia el artículo 27.3 de la Constitución.

Ley Orgánica 8/1985, de 3 de julio, reguladora del Derecho a la Educación. BOE núm. 159, de 4 de julio de 1985.

35 Artículo veinte.

$[\ldots]$

2. La admisión de los alumnos en los centros públicos, cuando no existan plazas suficientes, se regirá por los siguientes criterios prioritarios: rentas anuales de la unidad familiar, proximidad del domicilio y existencia de hermanos matriculados en el centro. En ningún caso habrá discriminación en la admisión de alumnos por razones ideológicas, religiosas, morales, sociales, de raza o nacimiento. Ley Orgánica 8/1985, de 3 de julio, reguladora del Derecho a la Educación. BOE núm. 159, de 4 de julio de 1985.
} 
y moral. Pero creemos que es interesante subrayar que, si bien la LODE y la LOECE habían vinculado siempre este derecho al 27.3 de la Constitución, aquí el legislador omite esta alusión y reconoce ese derecho «de acuerdo con las propias convicciones» dejando abierta la puerta a la interpretación de que así la norma se sitúa como vértice de la reforma al alumno. De hecho, sorprende que el artículo 27.3 no aparece en todo el texto. Otra novedad de la ley, a nuestro juicio muy relevante, es que fundamenta la enseñanza de la religión en los Acuerdos suscritos entre el Estado español y la Santa Sede, así como con «las otras confesiones religiosas ${ }^{36}$. Esta cuestión no es menor, ya que se evita vincular la existencia de la asignatura de religión con la Constitución. De esta manera, el derecho a recibir enseñanza religiosa encuentra su causa en los acuerdos firmados con las confesiones. Somos conscientes de que el 27.3 puede tener diversas interpretaciones ${ }^{37} \mathrm{y}$, aunque como he dicho

36 Apenas dos años más tarde se aprobarían las leyes 24,25 y 26 de 1992. Ley 24/1992, de 10 de noviembre, por la que se aprueba el Acuerdo de Cooperación del Estado con la Federación de Entidades Religiosas Evangélicas de España. BOE núm. 272, de 12 de noviembre de 1992; Ley 25/1992, de 10 de noviembre, por la que se aprueba el Acuerdo de Cooperación del Estado con la Federación de Comunidades Israelitas de España. BOE núm. 272, de 12 de noviembre de 1992 y Ley 26/1992, de 10 de noviembre, por la que se aprueba el Acuerdo de Cooperación del Estado con la Comisión Islámica de España.

37 Puede quedar circunscrito ese derecho al ámbito de las relaciones paternofiliales, como sugiere Cubillas. Puede vincularse con la asignatura de religión confesional en la escuela y, también con otros derechos de carácter educativo tal y como hace nuestro Tribunal Supremo en su sentencia 15 febrero de 1986 (524). En ella el Supremo establece que el artículo 27.6, por el que se reconoce la libertad de creación de centros docentes es la manifestación primaria de la libertad de enseñanza, pues supone la inexistencia de un monopolio estatal docente y en sentido positivo la existencia de un pluralismo educativo institucionalizado. Es a través del citado precepto, en el que se proclama la libertad de enseñanza y de creación de centros educativos, como puede satisfacerse ese otro derecho fundamental recogido en el artículo 27.3 que tienen los padres a que se les dé a sus hijos una formación religiosa y moral que está de acuerdo con sus convicciones. Mariano Cubillas Recio. "La enseñanza de la religión en el sistema español y su fundamentación en el derecho de los padres sobre la formación religiosa de sus hijos". Laicidad y Libertades. Escritos Jurídicos 2 (2002) 157-219. Llamazares señala que todos los grandes debates sobre el tema tienen su raíz en la distinta manera de entender la relación entre el derecho a la educación y la libertad de enseñanza. El mismo autor señala que los defensores de la enseñanza privada insisten en la prioridad de la libertad de enseñanza entendido como libertad de creación de centros de enseñanza con un ideario determinado, lo que daría lugar a una «pluralidad de escuelas» y facilita el derecho de los padres a elegir la educación 
en otras ocasiones, estoy de acuerdo con aquellos autores ${ }^{38}$ que afirman que, de la lectura del artículo aludido, no se infiere una exigencia constitucional encaminada a la implantación de la asignatura de religión en los centros docentes, es necesario recordar que, de la misma manera, no se encuentra en la CE una prohibición, la laicidad estatal tampoco lo impide ${ }^{39}$. Sin embargo, los acuerdos de 1992 parecen contradecir esta idea ya que aluden directamente al texto constitucional y vinculan el derecho a recibir enseñanza religiosa con el artículo 27.3 de la Carta Magna $^{40}$. En el mismo sentido se ha manifestado desde el principio el

más acorde con las propias convicciones y, en definitiva, con su propia conciencia. La postura opuesta la tienen aquéllos que apuestan por la enseñanza pública, éstos «insisten en el derecho a la educación en la libertad y para la libertad del educando, a lo que contribuye más eficazmente "el pluralismo en la escuela" y la enseñanza neutral que el "pluralismo de escuelas" »: Dionisio Llamazares Fernández. Derecho de la libertad de conciencia II. Madrid: Civitas, 1999, 41.

38 Por señalar sólo a algunos: Mariano Cubillas Recio, "La enseñanza de la religión...”, cit., 178, Iván C. Ibán. Derecho eclesiástico, o. c. , 148; José María Martí. “El nuevo perfil de la enseñanza religiosa en la reforma del sistema educativo no universitario". Anuario de Derecho Eclesiástico del Estado 8 (1992) 73; Ana Fernández-Coronado González. "Libertad de enseñanza (Derecho Eclesiástico)". En Enciclopedia Jurídica Básica III, Madrid, 1995, 4034.

39 El Tribunal Constitucional en su sentencia 31/2018, de 10 de abril avaló la inserción de una asignatura de religión en la escuela. Remitiéndose a su STC 38/2007, de 15 de febrero, FJ 5, explicó que su inclusión sólo puede ser, evidentemente, en régimen de seguimiento libre (STC 5/1981, de 13 de febrero, FJ 9). Además, según el TC «hace posible tanto el ejercicio del derecho de los padres de los menores a que éstos reciban la enseñanza religiosa y moral acorde con las convicciones de sus padres (art. 27.3 CE), como la efectividad del derecho de las Iglesias y confesiones a la divulgación y expresión públicas de su credo religioso, contenido nuclear de la libertad religiosa en su dimensión comunitaria o colectiva (art. 16.1 CE)». No creemos que esta afirmación sea contraria a nuestra postura cuando decimos que el artículo 27.3 no obliga, pero sí habilita. Por otro lado, si bien es cierto que la trasmisión de valores y enseñanza religiosa se configura en nuestro ordenamiento como un derecho también de las confesiones y su ejercicio no puede ir en detrimento del derecho de libertad religiosa de los individuos.

A continuación, el TC insistirá en la función promocional del Estado y relaciona la cooperación del 16.3 con esa exigencia a los poderes públicos y sugiere que «el deber de cooperación establecido en el art. 16.3 CE encuentra en la inserción de la religión en el itinerario educativo un cauce posible para la realización de la libertad religiosa en concurrencia con el ejercicio del derecho a una educación conforme con las propias convicciones religiosas y morales».

40 Comparto las observaciones que a este respecto realiza Polo cuando afirma que: «El art. 27 de la Constitución española, como es notorio, no menciona expresamente 
TC. En su sentencia de febrero 5/1981, el TC señalaba que la enseñanza religiosa que, con carácter optativo para el alumnado, se imparta en los centros públicos tienen cabida en el marco de una Estado laico ya que las enseñanzas de seguimiento libre sirven para hacer posible el derecho de los padres a elegir para sus hijos la formación religiosa y moral que esté de acuerdo con sus propias convicciones (art. 27.3 de la Constitución $)^{41}$. En definitiva, nuestra opinión puede resumirse en lo siguiente: el texto constitucional no obliga, pero habilita al legislador para incluir una asignatura de carácter confesional.

Sabemos, como ha sugerido Suárez Pertierra, que el desarrollo reglamentario de la LOGSE supuso un vuelco que removió los cimientos de la asignatura de religión. Se eliminaba la alternativa a la asignatura de la religión y, a pesar de que continuaba siendo evaluable, carecía de peso en los expedientes académicos, no «computaba» para las convocatorias realizadas por las administraciones públicas en el ámbito educativo ${ }^{42}$. El Tribunal Supremo (TS) resolvió los recursos planteados decretando la ilegalidad del régimen establecido para la asignatura de religión. Se apreció

la enseñanza de la religión en los centros educativos de titularidad pública, pero consagra, sin embargo, en su apartado tercero, el derecho de los padres a que sus hijos reciban la formación moral y religiosa que esté de acuerdo con sus convicciones. Este último derecho, por su parte, se encuentra inicialmente desarrollado en la Ley Orgánica 7/1980, de 5 de julio, de Libertad Religiosa, cuyo art. 2 contempla, como parte del contenido de esta libertad, el derecho de toda persona "a recibir e impartir enseñanza a información religiosa de toda índole, ya sea oralmente, por escrito o por cualquier otro procedimiento; elegir para sí, y para los menores no emancipados e incapacitados, bajo su dependencia, dentro y fuera del ámbito escolar, la educación religiosa y moral que esté de acuerdo con sus propias convicciones". Además, junto a las disposiciones que unilateralmente han concretado el régimen de ejercicio de este derecho en el marco de la legislación educativa, el Estado ha suscrito una serie de acuerdos con las confesiones religiosas, tanto con la Iglesia católica como con las llamadas confesiones minoritarias, en los que también este tema ha sido objeto de regulación específica, y en dichos acuerdos la enseñanza religiosa en la escuela pública aparece igualmente vinculada al derecho de los padres sobre la educación moral y religiosa de sus hijos constitucionalmente reconocido en el art. 27”. José Ramón Polo Sabau. "La enseñanza de la religión en la escuela pública: fundamento constitucional y desarrollo normativo". Revista General de Derecho Administrativo 33 (2013): 2.

41 STC 5/1981.

42 Gustavo Suárez Pertierra. "La enseñanza de la religión en el sistema educativo español”. En Laicidad, educación y democracia, coordinado por Patricio de Blas Zabaleta, 144. Madrid: Biblioteca Nueva, 2005. 
que el modelo adolecía de «falta de equiparabilidad y de concreción de las actividades alternativas» y, por ello, se generaba una lesión de legalidad vigente. También se consideró conculcado el principio de igualdad. Los fundamentos no se ampararon en la falta de entidad de la alternativa sino justamente lo contrario. La sentencia aclaró que la opción alternativa colocaba a quienes optaban por cursar la asignatura de religión en posición de adquirir mejor formación en las enseñanzas mínimas que aquellos alumnos que cursen religión y, por tanto, no pueden adquirir esta especie de formación suplementaria"43. El fallo del Supremo obligó a la aprobación de un nuevo Real Decreto ${ }^{44}$. Cierto es que, de nuevo, se plantearon ante el Tribunal Supremo distintos recursos. Sin embargo, en esta ocasión, el Tribunal los desestimó. De esta manera, la enseñanza de la religión, incluyendo en esta ocasión las opciones musulmana, judía y protestante, comenzó a impartirse con un nuevo planteamiento.

Las actividades extraescolares, la autonomía de gestión de los centros docentes, las inspecciones por parte de las Administraciones Educativas y los Órganos de Gobierno de los Centros Docentes Públicos serán desarrolladas, en 1995, por la Ley de Participación y Evaluación y Gobierno de los Centros Docentes (LOPEG). La Ley Orgánica de la Calidad de la Educación (LOCE), aprobada en 2002, no llegará a implantarse, siendo modificada en 2006 por la Ley Orgánica de Educación (LOE). Creemos, sin embargo, que las novedades que introdujo esta norma son merecedoras de unas líneas en este trabajo.

En su exposición de motivos, la LOCE explicaba que, en los niveles de Educación Primaria y de Educación Secundaria, la Ley confiere a las enseñanzas de las religiones y de sus manifestaciones culturales el tratamiento académico que le corresponde. Esto lo hace porque considera que esa formación es necesaria para una formación integral. Aquí no se plantea que la religión está presente porque está así recogido en los acuerdos, sino porque es fundamental en la formación de los alumnos. A continuación, aclara que se incluirá eso sí según lo dispuesto en los acuerdos. Pudiera parecer que dice lo mismo que la LOGSE, que vincula la enseñanza de la religión con la existencia de los acuerdos, a mi parecer nada más lejos de la realidad. La ley en primer lugar concede importancia

43 Ibidem, 147.

44 Real Decreto 2438/1994, de 16 de diciembre, por el que se regula la enseñanza de la Religión, BOE núm. 22, de 26 de enero de 1995. 
a la enseñanza de la religión, ésa es la razón por la que se incluye en el currículo, y lo pactado con las confesiones no será sino el modo en que la asignatura deberá implementarse. Reconoce la libertad religiosa de los alumnos y el deber de aquéllos de respetar la libertad de conciencia y las convicciones morales y religiosas de los demás, y entre los derechos de los padres cita el recogido en el 27.3 sin nombrarlo. La importancia dada a la formación religiosa de los estudiantes tiene su reflejo en la creación del área o asignatura de Sociedad, Cultura y Religión. Ésta dispondrá de dos opciones: la de carácter confesional y otra no confesional. Si la primera deberá regirse por lo dispuesto en los acuerdos con las confesiones religiosas, en ésta última será el Gobierno el encargado de fijar las enseñanzas comunes correspondientes a la opción no confesional ${ }^{45}$.

La LOE incluyó, como la mayoría de sus predecesoras, la protección del sentimiento religioso en el ámbito educativo prohibiendo la discriminación por motivos religiosos, realizando, de esta manera, un refuerzo

45 Disposición adicional segunda. Del área o asignatura de Sociedad, Cultura y Religión.

1. El área o asignatura de Sociedad, Cultura y Religión comprenderá dos opciones de desarrollo: Una, de carácter confesional, acorde con la confesión por la que opten los padres o, en su caso, los alumnos, entre aquéllas respecto de cuya enseñanza el Estado tenga suscritos acuerdos; otra, de carácter no confesional. Ambas opciones serán de oferta obligatoria por los centros, debiendo elegir los alumnos una de ellas.

2. La enseñanza confesional de la Religión se ajustará a lo establecido en el Acuerdo sobre enseñanza y asuntos culturales suscrito entre la Santa Sede y el Estado español y, en su caso, a lo dispuesto en aquellos otros suscritos, o que pudieran suscribirse, con otras confesiones religiosas.

3. El Gobierno fijará las enseñanzas comunes correspondientes a la opción no confesional. La determinación del currículo de la opción confesional será competencia de las correspondientes autoridades religiosas. Las decisiones sobre utilización de libros de texto y materiales didácticos y, en su caso, la supervisión y aprobación de los mismos corresponden a las autoridades religiosas respectivas, de conformidad con lo establecido en los Acuerdos suscritos con el Estado español.

4. Los profesores que, no perteneciendo a los Cuerpos de Funcionarios Docentes, impartan la enseñanza confesional de Religión en los centros públicos en los que se desarrollan las enseñanzas reguladas en la presente Ley, lo harán en régimen de contratación laboral, de duración determinada y coincidente con el curso escolar, a tiempo completo o parcial. Estos profesores percibirán las retribuciones que corresponda en el respectivo nivel educativo a los profesores interinos.

Ley Orgánica 10/2002, de 23 de diciembre, de Calidad de la Educación. BOE núm. 307, de 24 de diciembre de 2002 
al mandato constitucional del artículo $14^{46}$. La disposición adicional segunda, justificará la enseñanza confesional remitiendo, como ya hiciera la LOGSE, a lo dispuesto en los acuerdos con la Santa Sede y los aprobados en 1992 con la Federación de Entidades Religiosas Evangélicas de España, la Federación de Comunidades Israelitas de España, la Comisión Islámica de España y, en su caso, a los que en el futuro puedan suscribirse con otras confesiones religiosas ${ }^{47}$. La LOE dedica una disposición adicional expresamente a los profesores de religión, ésta abrió paso al cambio que sufrirían las condiciones laborales de este cuerpo un año después ${ }^{48}$. Sería imperdonable hablar de la LOE y obviar el debate que surgió con la asignatura de Educación para la ciudadanía. Sin relación directa con la asignatura de Religión, pero con un nexo evidente con las creencias de los ciudadanos, «educación para la ciudadanía» tuvo un tremendo impacto. Como señala Ciáurriz ${ }^{49}$, la implantación de la asignatura no fue recibida de manera pacífica por el total de la sociedad. Un elevado número de padres decidió invocar la objeción de conciencia y se negaron a que sus hijos cursaran Educación para la ciudadanía. En

46 En concreto lo recoge en el artículo 84 que es el que trata de la admisión de alumnos en centros públicos y privados concertados:

Artículo 84. Admisión de alumnos.

[...]

3. En ningún caso habrá discriminación por razón de nacimiento, raza, sexo, religión, opinión o cualquier otra condición o circunstancia personal o social. Ley Orgánica 2/2006, de 3 de mayo, de Educación. BOE núm. 106, de 4 de mayo de 2006.

47 Disposición adicional segunda. Enseñanza de la religión.

1. La enseñanza de la religión católica se ajustará a lo establecido en el Acuerdo sobre Enseñanza y Asuntos Culturales suscrito entre la Santa Sede y el Estado español. A tal fin, y de conformidad con lo que disponga dicho acuerdo, se incluirá la religión católica como área o materia en los niveles educativos que corresponda, que será de oferta obligatoria para los centros y de carácter voluntario para los alumnos.

2. La enseñanza de otras religiones se ajustará a lo dispuesto en los Acuerdos de Cooperación celebrados por el Estado español con la Federación de Entidades Religiosas Evangélicas de España, la Federación de Comunidades Israelitas de España, la Comisión Islámica de España y, en su caso, a los que en el futuro puedan suscribirse con otras confesiones religiosas. Ley Orgánica 2/2006, de 3 de mayo, de Educación. BOE núm. 106, de 4 de mayo de 2006.

48 Real Decreto 696/2007, de 1 de junio, por el que se regula la relación laboral de los profesores de religión prevista en la disposición adicional tercera de la Ley Orgánica 2/2006, de 3 de mayo, de Educación. BOE núm. 138, de 9 de junio de 2007.

49 María José Ciáurriz Labiano. "La objeción de conciencia”. En Derecho eclesiástico del Estado, coordinado por Gustavo Suárez Pertierra, cit., 139-168. 
febrero de 2009, el Tribunal Supremo defendió, sin fisuras, la asignatura de Educación para la ciudadanía, destacando que su contenido no suponía un "adoctrinamiento lesivo» ni vulnera la libertad ideológica y religiosa, ni el derecho de los padres a que sus hijos reciban la formación religiosa y moral acorde con sus convicciones. El futuro de la asignatura en Ley Orgánica para la Mejora de la Calidad Educativa (LOMCE), pasó por integrar sus contenidos de manera transversal dando lugar a su desaparición como disciplina autónoma ${ }^{50}$.

Como hemos dicho, son los acuerdos con las confesiones religiosas - y no la Constitución - los instrumentos jurídicos que determinan la existencia de la asignatura de religión en la escuela. La LOMCE cita los acuerdos en su disposición adicional segunda y establece que «la enseñanza de la religión católica se ajustará a lo establecido en el Acuerdo sobre Enseñanza y Asuntos Culturales suscrito entre la Santa Sede y el Estado español. También la enseñanza de otras religiones se ajustará a lo dispuesto en los Acuerdos de Cooperación celebrados por el Estado español», que, de momento, y como ya sabemos, son con la Federación de Entidades Religiosas Evangélicas de España, la Federación de Comunidades Israelitas de España, la Comisión Islámica de España y, en su caso, a los que en el futuro puedan suscribirse con otras confesiones religiosas. Este último apartado refuerza la idea de que el legislador —al menos hasta el momento- ha vinculado la asignatura de Religión a la firma de acuerdos, aunque no los cite, en esta ocasión, como causa de la misma, sino como marco para su implementación.

Así las cosas, en la etapa de educación primaria los padres, madres o tutores legales podrán elegir entre Religión o Valores Sociales y Cívicos; en el primer ciclo de Educación Secundaria Obligatoria (ESO) y cuarto

${ }^{50}$ Las únicas acciones que están dificultando tal desaparición son las llevadas a cabo por algunos centros, asociaciones y entidades que están intentando mantenerla por medio de talleres y actividades extraescolares (FETE-UGT, 24 de junio de 2015 y Fundación Cives, 3 de julio de 2014) y las emprendidas por algunos gobiernos autonómicos, que en su momento pudieron ser de ideología opuesta a la del Partido Popular, que han buscado estrategias para mantenerla en los planes de estudio. Por ejemplo, Andalucía, que se resistía a aplicar la LOMCE y continuó impartiendo Educación para la Ciudadanía por medio del bloque de materias de libre configuración autonómica, y, tras las elecciones autonómicas y municipales de mayo de 2015, algunas otras comunidades autónomas como Aragón. 
curso de la ESO, los padres, tutores o, en su caso, el alumno o la alumna, podrán elegir entre Religión o Valores Éticos. De esta manera la LOMCE parece retrotraerse al sistema previo a la LOGSE. Por último, «la determinación del currículo y de los estándares de aprendizaje evaluables que permitan la comprobación del logro de los objetivos y adquisición de las competencias correspondientes a la asignatura Religión será competencia de las respectivas autoridades religiosas. Las decisiones sobre utilización de libros de texto y materiales didácticos y, en su caso, la supervisión y aprobación de los mismos corresponden a las autoridades religiosas respectivas, de conformidad con lo establecido en los Acuerdos suscritos con el Estado español».

En diciembre de 2020 se aprueba la que, hasta ahora, se ha convertido en la última reforma educativa. Planteada como una reforma de la LOE, la LOMLOE nace entre polémica y con el anuncio de los medios de comunicación de un nuevo escenario para la asignatura de Religión confesional $^{51}$. Lo cierto es que la ley reconoce como perceptible el factor religioso y concede una representación, no menor, a las creencias de los miembros de la comunidad educativa. Refuerza, como ya hiciera la LOMCE, el mandato de no discriminación constitucional en distintos apartados y se concede especial importancia a que la acción educativa esté orientada a comprender y respetar las diferentes culturas y diferencias entre las personas concediendo de manera implícita una gran importancia a la gestión de la diversidad en el ámbito educativo. Pero, quizá lo más significativo de esta ley en la cuestión que nos ocupa es la recuperación de la enseñanza de las religiones desde la perspectiva no confesional. Esta vez, sin embargo, no se plantea como alternativa, ni siquiera es un mandato a las autoridades educativas, la ley parece plantearlo como una opción. Así, la nueva redacción del apartado 3 de la disposición adicional segunda establece que «en el marco de la regulación de las enseñanzas

51 A modo de ejemplo: https://www.eldiario.es/sociedad/educacion-lomce-religion-segregacion_1_1049409.html, últ. 12, septiembre 2020; https:/www.elespanol.com/ reportajes/20200303/religion-gran-maria-celaa-paulo-profesores-temen/471704270_0. html https:/www.elespanol.com/reportajes/20200303/religion-gran-maria-celaa-paulo-profesores-temen/471704270_0.html, últ. 12, septiembre 2020; https://www. elespanol.com/reportajes/20200303/religion-gran-maria-celaa-paulo-profesores-temen/471704270_0.html; https://www.heraldo.es/noticias/nacional/2021/02/24/profesores-de-religion-piden-a-celaa-un-minimo-de-dos-horas-semanales-de-la-asignatura-1473103.html 
de Educación Primaria y Educación Secundaria Obligatoria, se podrá establecer la enseñanza no confesional de cultura de las religiones». Refuerza también el derecho de los padres a educar a los hijos conforme a su ideología religión o creencias. Y, como ya hicieran otras leyes, reconoce el derecho de libertad religiosa de los alumnos y su obligación de respetar las de los demás.

\section{EL MANDATO DEL 16.3 A LOS PODERES PÚBLICOS Y EL FACTOR RELIGIOSO EN LA ESCUELA. MÁS ALLÁ DE LA INSTRUCCIÓN}

Parece claro que la evolución de las normas educativas muestra un cambio en el papel de los poderes públicos respecto del factor religioso en el ámbito escolar. Hemos probado que España ya no es una sociedad homogénea en materia de creencias. Por el contrario, nuestro país es ahora una sociedad plural en la que los ciudadanos, como portadores de identidades fuertes ${ }^{52}$, configuran un crisol de culturas en el que se hacen presentes distintas opciones en materia religiosa. Esta realidad obliga a los actores sociales a generar nuevos sistemas de gestión que permitan el ejercicio de la libertad religiosa sin que esto sea una cuestión controvertida ${ }^{53}$.

La importancia del paso de una sociedad con una fuerte herencia confesional, a una multicultural no ha tenido aún reflejo en todas las actuaciones de los poderes públicos. En concreto, las autoridades educativas apenas han afrontado la cuestión de las creencias más que con la implementación de la asignatura de religión confesional. La homogeneidad social y el predominio de la Iglesia católica, amparadas en la herencia de

52 Silvio Ferrari. "Introducción". En Derecho y Religión en Europa occidental, S. Ferrari y I. C. Ibán. Madrid: McGraw-Hill, 1998.

53 La necesidad de esta cuestión ha sido planteada en distintos trabajos, sirvan como muestra: Irene M. Briones Martínez. "Inmigración e interculturalidad". En Algunas cuestiones controvertidas del ejercicio del derecho fundamental de libertad religiosa en España, coordinado por Isidoro Martín Sánchez y Marcos González Sánchez, 361-390. Madrid: Fundación Universitaria Española, 2009; Margarita Lema Tomé. Laicidad e integración de los inmigrantes. Madrid: Marcial Pons, 2007; María Cruz Llamazares Calzadilla. "Extranjería y derecho de libertad religiosa". En Tratado de extranjería: aspectos civiles, penales, administrativos y sociales, coordinado por Alberto Palomar Olmeda, 709-728. Madrid: Aranzadi, 2004; Beatriz Souto Galván. "Multiculturalismo y pluralismo religioso". Derecho y opinión 8 (2000): 543-548. 
un sistema confesional, no precisaba atender el factor religioso de otra manera en la escuela. Por mejor decir: las creencias estaban «insertadas» en el sistema educativo. Las costumbres religiosas eran compartidas por los miembros de la comunidad educativa, las festividades nacionales, autonómicas o locales, coincidían con la práctica religiosa, las tradiciones y los símbolos también. Así las cosas, aparentemente el factor religioso no era perceptible en la escuela y, sin embargo, estaba constantemente presente, aunque su más clara manifestación lo era la asignatura de religión confesional. Como hemos dicho, desde la aprobación de la Constitución se ha visto amparada en muchas ocasiones en el artículo 27.3. Sin embargo, encuentra su verdadero anclaje en el Acuerdo de Enseñanza y Asuntos culturales con la Santa Sede de 1979, donde se fija el régimen que después se intentará hacer extensivo a otras confesiones religiosas y que se materializó en las leyes 24, 25 y 26 de 1992. Aunque, como ya hemos puesto de manifiesto, la CE no obliga a incluir una asignatura de carácter apologético, tampoco se puede sostener que la laicidad que propugna el artículo 16.1 vete la enseñanza de la religión en la escuela ${ }^{54}$, aunque sea confesional. A nuestro juicio, son los matices en la implementación

54 Polo lo dice así: «Así pues, en términos jurídicos, tan equivocado es sostener que la Constitución española (La Ley 2500/1978) obliga a que los colegios públicos oferten obligatoriamente la asignatura de religión —católica o la de cualquier otra- como lo es también, inversamente, postular que el derecho de los padres a que sus hijos reciban la formación religiosa acorde a sus convicciones no es un derecho constitucional, tal y como inopinadamente hizo la actual ministra de Educación hace unos meses, en unas declaraciones públicas como mínimo sorprendentes que, a muchos juristas, nos causaron verdadera estupefacción. Por todo ello, en mi criterio, incluso una hipotética eliminación de nuestro sistema educativo de la obligación de ofertar la asignatura de religión católica en los centros públicos estaría amparada por nuestra Constitución, en tanto no estamos aquí en presencia de un derecho de prestación sino de uno de libertad. Lo que en todo caso sí podría postularse con algún fundamento es que esa hipotética circunstancia supondría una vulneración del correspondiente acuerdo con la Santa Sede, que es el que estableció el mandato de insertar esa asignatura en el currículo de los colegios públicos como tal disciplina de oferta obligatoria, en condiciones equiparables a las demás disciplinas fundamentales, y consagró con ello, en esta como en tantas otras materias, un privilegio del que sólo goza esta religión, lo cual, a su vez, ha suscitado algunas dudas muy razonables acerca de la adecuación de todo este régimen concordatario tanto al principio de igualdad y no discriminación como al de aconfesionalidad». José Ramón Polo Sabau. "A vueltas con la asignatura de religión tras la aprobación de la LOMLOE”. Diario La Ley, 9763 (2021): 1. 
de la materia los que determinarán la constitucionalidad o no del mode$1 \mathrm{o}^{55}$. Hemos visto, sin embargo, que el reflejo de la religión en las leyes educativas ha ido cambiando de manera paulatina, primero reiterando el respeto la libertad religiosa en el ámbito académico, así como la no discriminación por motivos religiosos hasta llegar a la aprobación de la LOMLOE. Ésta última trata de garantizar una estructura del currículo al servicio de una educación inclusiva y acorde con la adquisición de competencias, que valore además la diversidad ${ }^{56}$. Si bien estos cambios no son a nuestro juicio suficientes en lo que a enseñanza religiosa se refiere.

El artículo 16.3. reconoce la laicidad estatal; obliga a los poderes públicos a tener en cuenta las creencias religiosas de la sociedad española y a mantener relaciones de cooperación con la Iglesia católica y las demás confesiones. Aunque, en ocasiones se ha calificado al mandato constitucional como una disposición básica del ordenamiento eclesiástico español que proclama la relevancia específica del fenómeno social religioso ${ }^{57}$, en nuestra opinión ${ }^{58}$, el precepto tiene dos encargos con dos objetivos distintos: uno, tener en cuenta las creencias de la sociedad y otro, el de la cooperación con las Confesiones religiosas. El primer apartado, orientado a la protección de las creencias desde una perspectiva sociológica, no implica vinculación alguna con las confesiones religiosas, sino con los ciudadanos y sus creencias, no es «el fenómeno religioso» lo que se protege especialmente sino «las creencias». Los poderes públicos no pueden asumir una posición interesada y favorable

55 La posibilidad de crear un modelo de enseñanza confesional obligatoria, es el más claro ejemplo de asignatura incompatible con el régimen constitucional.

56 Cierto es que tanto la ley como las autoridades educativas al hablar de diversidad se refieren generalmente a la diversidad de capacidades intelectuales del alumnado dedicando un pequeño esfuerzo a otros tipos de diversidad.

57 Mariano López Alarcón. “Actitud del Estado ante el factor religioso”. Anuario de Derecho Eclesiástico del Estado 5 (2008): 64.

58 He tenido ocasión de explicar esta teoría más detalladamente en: Almudena Rodríguez Moya. "La gestión de la diversidad religiosa: una nueva realidad social vs. ¿una nueva realidad jurídica?”. En Religión, matrimonio y Derecho ante el siglo XXI: Estudios en homenaje al Profesor Rafael Navarro-Valls, coordinado por Javier Martínez Torrón, Silvia Meseguer Velasco y Rafael Palomino Lozano, Vol. 1, 1445-1459. Madrid: Iustel, 2013; Almudena Rodríguez Moya. "Evolución y vigencia del principio de cooperación entre el Estado y las confesiones religiosas”. En Derecho canónico en tiempos de cambio: actas de las XXX Jornadas de Actualidad Canónica, coord. por Jorge Otaduy Guerín, 109-124. Madrid: Dykinson, 2011. 
respecto del fenómeno religioso que obligara a los poderes públicos a promoverlo ${ }^{59}$. Y decimos que no puede porque a nuestro entender esta interpretación va más allá de lo que establece el texto constitucional. El 16.3. obliga a tener en cuenta las creencias, no el factor religioso y no es lo mismo. Las creencias son mutables y dependen de la profesión de fe de los ciudadanos, sin embargo, el factor religioso podría ser considerado inmutable, que existe al margen de las creencias de los ciudadanos. Esta idea nos podría llevar a una conclusión singular: aunque ningún ciudadano tuviera creencias religiosas, el Estado debería promover el factor religioso. Esta interpretación resulta claramente contraria a la voluntad del constituyente que propugna una laicidad positiva. En ese supuesto, precisamente, lo que se estaría haciendo es no tener en cuenta las creencias de la sociedad ${ }^{60}$. Lo que, sin duda, debe promover el Estado es la libertad religiosa de los individuos ${ }^{61}$ en tanto que derecho fundamental. Podemos afirmar, sin temor a equivocarnos, que lo que aquí se plantea es un refuerzo del derecho de libertad religiosa evitando así una laicidad al modo francés. Esta interpretación no está exenta de dificultad habida cuenta de la garantía de inmunidad que señala el propio precepto constitucional en su segundo apartado: «Nadie podrá ser obligado a declarar sobre su ideología, religión o creencias». ¿Cómo es posible tener en cuenta las creencias de los ciudadanos si aquéllos no las expresan? La respuesta es sencilla: no se puede. El precepto constitucional no exige mantener la fe en el terreno de lo íntimo, protege a los ciudadanos para que esto pueda ser asít ${ }^{2}$. Y, aunque la intención del constituyente no es en ningún modo vulnerar el principio de igualdad por razón de creencias, sí lo es el reconocimiento de aquéllas y la promoción del derecho de libertad religiosa ${ }^{63}$.

59 Mariano López Alarcón, “Actitud del Estado ante el factor religioso”, o. c., 64.

60 Somos conscientes de lo extremo que resulta el ejemplo, pero creemos que es adecuado para poner de manifiesto lo que supone una interpretación en ese sentido.

61 Iván C. Ibán. "Principios constitucionales del Derecho español”, Lecciones de Derecho eclesiástico, Iván C. Ibán y Luis Prieto Sanchís, 130. Madrid: Tecnos, 1990. En este sentido Cf. Abraham Barrero Ortega. La libertad religiosa en España. Madrid: Centro de Estudios Políticos y Constitucionales, 2006, 240.

62 Iván C. Ibán. "Fuentes". En Derecho Eclesiástico, Iván C. Ibán, Luis Prieto Sanchís y Agustín Motilla de la Calle, 107. Madrid 1997.

63 En este sentido ya lo dejó claro el TC en su STC 160/1987 aplicada al reconocimiento del derecho de objeción de conciencia. Así la idea de que el derecho, también el fundamental, excluye «toda regulación legal no parece conformarse con la técnica 
La CE, por tanto, obliga a los poderes públicos a tener en cuenta las creencias de la sociedad española y es nuestra opinión que, en el campo educativo, el mandato constitucional ha resultado olvidado. Quizá porque la cuestión religiosa en la escuela ha quedado reducida a la ya vieja polémica «clase de religión sí, clase de religión no». A este respecto, se abren varios interrogantes. ¿Cuáles son los «poderes públicos» que están obligados a tener en cuenta las creencias de los miembros que conforman la comunidad educativa? ¿Cuáles son las medidas que se podrían implementar para hacer efectivo el mandato constitucional? ¿Afectarían esas decisiones exclusivamente al currículo?

El modelo descentralizado que establece la CE plantea una distribución del Estado en función del territorio: las comunidades autónomas (CC. AA.), las provincias y los municipios. Se trata de entidades de distinto nivel que son fundamentalmente el Estado, titular de la soberanía ${ }^{64}$, configurando un sistema multinivel de distribución de competencias ${ }^{65}$. La LOMLOE establece las competencias del Gobierno, a través del que, en la actualidad toma el nombre de Ministerio de Educación y Formación Profesional ${ }^{66}$. Y le corresponde la ordenación general del sistema educativo; la programación general de la enseñanza; la fijación de las enseñanzas mínimas o aspectos básicos del currículo; la regulación de las condiciones

constitucional: el propio art. 16 ya admite la entrada legislativa al determinar que las libertades que reconoce pueden ser limitadas por el orden público protegido por la Ley, lo que es independiente, por otra parte, de la mínima regulación precisa para que el derecho sea viable». STC 160/1987, de 27 de octubre.

64 STC 4/1981, de 2 de febrero. «la Constitución (arts. 1 y 2) parte de la unidad de la Nación española que se constituye en Estado social y democrático de Derecho, cuyos poderes emanan del pueblo español en el que reside la soberanía nacional. Esta unidad se traduce así en una organización —el Estado- para todo el territorio nacional. Pero los órganos generales del Estado no ejercen la totalidad del poder público, porque la Constitución prevé, con arreglo a una distribución vertical de poderes, la participación en el ejercicio del poder de entidades territoriales de distinto rango, tal como se expresa en el art. 137 de la Constitución al decir que "el Estado se organiza territorialmente en municipios, en provincias y en las Comunidades Autónomas que se constituyan"».

65 Para comprender el concepto del constitucionalismo multinivel, Yolanda Gómez Sánchez, Teresa Freixes Sanjuán y Antonio Rovira Viñas (Dirs.). Constitucionalismo multinivel y relaciones entre Parlamentos: Parlamento europeo, Parlamentos nacionales y Parlamentos regionales con competencias legislativas, 2013. Sobre CC. AA., cf. María Dolores Cebriá García. "La enseñanza de la religión en las Comunidades Autónomas”. Derecho y Religión 14 (2019): 53-76.

66 Nomenclatura el 15 septiembre de 2021. 
de obtención, expedición y homologación de títulos académicos y profesionales y la alta inspección para garantizar el cumplimiento de las obligaciones de los poderes públicos. Para las competencias de las CC. AA. la LOMLOE remite a los diferentes estatutos de autonomía, de tal manera que variará de una comunidad a otra. Además del Gobierno y las CC. AA., también involucrados en la gestión de la diversidad religiosa en la escuela, participan de la organización y administración general del sistema educativo las entidades locales y centros escolares ${ }^{67}$.

Los poderes públicos deben tener en cuenta las creencias de la sociedad española, en el ámbito académico aquéllos se encuentran representados por los miembros de las distintas administraciones educativas, Estado, CC. AA. y entidades locales y cuya representación se ostenta, además, por entidades y miembros de la comunidad educativa: centros educativos, directores, profesores, etc., a todos ellos concierne este mandato. En materia de creencias, y siendo la libertad religiosa un derecho fundamental, queda fuera de toda duda que sólo compete al Estado lo necesario para el desarrollo orgánico del citado derecho. Esto no significa que las CC. AA. no puedan regular los derechos fundamentales, las CC. AA. pueden aprobar normas relativas a los mismos, pero no su desarrollo ${ }^{68}$. Así ocurre también con el derecho a la educación.

De la misma manera y, como ya he tenido ocasión de señalar ${ }^{69}$, según establecía la Ley 7/1985, de 2 de abril, Reguladora de las Bases del Régimen Local, el municipio es el marco por excelencia de la convivencia civil. Es, además, el cauce más cercano de participación ciudadana en los asuntos públicos. Antes de la aprobación Ley 27/2013 el sistema competencial de los municipios era un modelo exageradamente complejo mediante el que la responsabilidad de las entidades locales quedaba completamente diluida y producía una enorme confusión con los ámbitos competenciales de otras Administraciones. En la actualidad las competencias de los municipios se encuentran delimitadas con claridad ${ }^{70}$ y entre ellas está la

67 Los Centros escolares participan a través de los proyectos educativos.

68 Agustín Motilla de la Calle. "La Ley Orgánica de Libertad Religiosa y las Comunidades Autónomas: la regulación autonómica de la libertad religiosa”. Anuario de Derecho Eclesiástico del Estado 26 (2010): 359-404.

69 Almudena Rodríguez Moya. “Ayuntamientos y religión: el creciente papel de las entidades locales en la cooperación religiosa”. Anuario de Derecho Eclesiástico del Estado 34 (2018): 331-356.

70 José María Souviron Morenilla. "Competencias propias y servicios mínimos obligatorios de los municipios en la reciente reforma del régimen local básico”. 
participación en la programación de la enseñanza y la cooperación con la Administración educativa en la creación, construcción y sostenimiento de los centros docentes públicos, así como la intervención en sus órganos de gestión y en la vigilancia del cumplimiento de la escolaridad obligatoria. La implicación con la gestión de la diversidad en el ámbito educativo es indirecta para los ayuntamientos, pero fundamental ${ }^{71}$.

Sin embargo, no acaban ahí las responsabilidades, los centros educativos tienen encomendada la aprobación de su proyecto educativo que «recogerá los valores, los fines y las prioridades de actuación, incorporará la concreción de los currículos establecidos por la Administración educativa, que corresponde fijar y aprobar al Claustro, e impulsará y desarrollará los principios, objetivos y metodología propios de un aprendizaje competencial orientado al ejercicio de una ciudadanía activa. Asimismo, incluirá un tratamiento transversal de la educación en valores, del desarrollo sostenible, de la igualdad entre mujeres y hombres, de la igualdad de trato y no discriminación y de la prevención de la violencia contra las niñas y las mujeres, del acoso y del ciberacoso escolar, así como la cultura de paz y los derechos humanos», entre ellos, la libertad religiosa. Y, aunque la LOE definió a las Administraciones educativas como los órganos de la Administración General del Estado y de las Administraciones de las Comunidades Autónomas competentes en materia educativa, creemos que no podemos tampoco olvidar que también forman parte del sistema educativo profesionales de la educación y otros agentes, públicos y privados, que desarrollan funciones de regulación, de financiación o de prestación de servicios para el ejercicio del derecho a la educación en España, y los titulares de este derecho, así como el conjunto de relaciones, estructuras, medidas y acciones que se desarrollen al efecto ${ }^{72}$. A todos ellos entende-

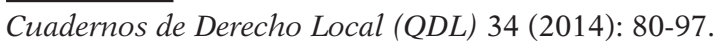

71 https://www.observatorioreligion.es/upload/96/88/Manual_gestion_municipal. pdf, últ. 13 septiembre 2021.

72 Dos. Se modifican los apartados 1 y 3 del artículo 2 bis con la siguiente redacción:

«1. A los efectos de esta Ley, se entiende por Sistema Educativo Español el conjunto de Administraciones educativas, profesionales de la educación y otros agentes, públicos y privados, que desarrollan funciones de regulación, de financiación o de prestación de servicios para el ejercicio del derecho a la educación en España, y los titulares de este derecho, así como el conjunto de relaciones, estructuras, medidas y acciones que se desarrollen al efecto.» Ley Orgánica 3/2020, de 29 de diciembre, por la que se modifica la Ley Orgánica 2/2006, de 3 de mayo, de Educación. BOE núm. 340, de 30 de diciembre de 2020. 
mos que concierne el mandato constitucional, por lo que están obligados a tener en cuenta las creencias, en este caso de la comunidad educativa.

\section{LOMLOE, RELIGIÓN Y RELIGIONES}

El hecho religioso se hace perceptible en la escuela desde una doble perspectiva, la meramente educativa, de transmisión de conocimientos y la del reconocimiento de la diversidad religiosa en la convivencia escolar. Ambas cuestiones están relacionadas.

El derecho a recibir e impartir enseñanza religiosa forma parte del contenido esencial de la libertad ideológica, religiosa y de culto reconocida a los individuos, siempre que se trate de una enseñanza confesional. En España, como hemos visto, el régimen de la asignatura viene determinado por lo pactado con las confesiones religiosas con acuerdo: la Iglesia católica, las Iglesias evangélicas, las comunidades judías y las comunidades musulmanas y respaldado por el artículo 16.1 de la Constitución. Nada que ver con planteamiento de los principios orientadores de Toledo (2008) que fueron elaborados para contribuir a una mejor comprensión de la creciente diversidad religiosa en el mundo y de la presencia cada vez más patente de la religión en el ámbito público. Aunque estos principios pueden, y quizá deben ser, compatibles con una enseñanza confesional de lo religioso. En este caso, la razón de ser de la formación religiosa descansa en dos necesidades clave: el carácter positivo de una enseñanza que haga hincapié en el respeto del derecho de todos a la libertad religiosa y de creencias; y la capacidad de la enseñanza sobre las religiones y creencias para reducir los malentendidos y estereotipos. Coincidimos con Otaduy cuando dice que, en España, «la asignatura fue concebida —nunca se planteó otra posibilidad-como de índole confesional: es decir, enseñanza de "doctrina católica". Se trata de un elemento llamado a condicionar de manera decisiva el régimen jurídico de la disciplina y de su profesorado » ${ }^{73}$. En el mismo sentido se negoció en 1992 de tal manera

73 Jorge Otaduy Guerin. "La idoneidad de los profesores de religión católica y su desarrollo jurisprudencial en España”. Estudios eclesiásticos: Revista de investigación e información teológica y canónica 88, n. ${ }^{\circ} 347$ (2013): 850. Acerca de las dificultades que plantea el modelo, Cf. Miguel Rodríguez Blanco. "Breves consideraciones sobre la idoneidad de los profesores de religión en centros docentes públicos: a propósito de la Sentencia del Tribunal Superior de Justicia de Canarias, Sala de lo Social, de 
que es razonable la intervención de las confesiones en el contenido y la selección del profesorado.

Se ha criticado mucho el modelo de asignatura de Religión confesional que hemos desarrollado en estas páginas. Compatible con la laicidad estatal y, aunque orientada al fiel, creemos que, a la luz de la nueva realidad social en materia religiosa, combinando ésta con el factor migratorio, pensamos que puede defenderse su inclusión en los planes de estudio, como vehículo de integración. Sería imperdonable olvidar la importancia que ha tenido la religión en las comunidades migrantes, ya lo hemos dicho, en la mayoría de las ocasiones actúa, además, como vínculo con la sociedad de origen. La religión contribuye a mantener señas de identidad y creencias heredadas. Además, la pertenencia a una fe no puede disociarse del espacio social que representan las iglesias y comunidades de creyentes. Esto, en el ámbito escolar cobra una importancia mayúscula, ofreciendo al estudiante un espacio conocido que, de alguna manera, puede servirle de refugio ${ }^{74}$. En definitiva, estamos afirmando que además de hacer efectivo el derecho a recibir enseñanza religiosa, la asignatura de religión confesional, puede ofrecer beneficios colaterales que, ahora sí, servirían para hacer efectivo el espíritu de los principios orientadores de Toledo sobre la enseñanza acerca de religiones y creencias en las escuelas públicas, toda vez que los movimientos migratorios, la ruptura de la unidad de fe en distintos Estados, y algunas ideas equivocadas sobre

17 de julio de 2007". Revista General de Derecho Canónico y Derecho Eclesiástico del Estado 16 (2008); Ángel López-Sidro López. "Impacto de la doctrina del TEDH en la jurisprudencia española: la idoneidad y el vínculo de especial confianza del profesorado de religión”. Anuario de derecho eclesiástico del Estado 34 (2018): 469-527; Joaquín Mantecón Sancho. "La enseñanza religiosa de las confesiones minoritarias en los Acuerdos de cooperación de 1992". Revista General de Derecho Canónico y Derecho Eclesiástico del Estado 44 (2017); Rafael Palomino Lozano. "Profesores de religión en la escuela pública: autonomía de los grupos religiosos, neutralidad del estado y desconcierto final". Revista General de Derecho Canónico y Derecho Eclesiástico del Estado 43 (2017); Gloria Moreno Botella. "Profesores de religión: tres sentencias y un mismo fallo a favor de la autonomía confesional en el TEDH (un posible paradigma de solución para el caso Pavez)". Persona y derecho: Revista de fundamentación de las Instituciones Jurídicas y de Derechos Humanos 77 (2017): 271-308.

74 Realiza un análisis de la cuestión Miguel Ángel Santos Rego. "La educación intercultural y el pluralismo religioso: Propuestas pedagógicas para el diálogo”. En "El centro educativo ante la diversidad". Educación XXI: Revista de la Facultad de Educación 20 (2017): 17-35. 
algunas religiones y prácticas culturales, han puesto de manifiesto la necesidad de apostar por la tolerancia social y resaltar la importancia de la libertad religiosa y su ejercicio ${ }^{75}$.

La Organización de Seguridad y Cooperación en Europa (OSCE) ha convertido estas cuestiones en prioridad y ha solicitado a los Estados que elaboren estrategias nacionales de educación para prevenir la discriminación y la intransigencia religiosas. En el citado documento se ofrece una descripción de las cuestiones jurídicas a tener en cuenta a la hora de formar profesores y elaborar planes de estudios sobre enseñanza de las religiones. Precisamente para respetar la legalidad vigente y el mandato constitucional, resultaría oportuno realizar políticas educativas que ofrezcan soluciones a las necesidades de los alumnos como sujetos de fe. Estas medidas contribuirán, sin duda, a la mejora de la convivencia en las aulas que podrá trasladarse a otros ámbitos.

Desde el punto de vista estrictamente formativo, el factor religioso aparece ahora en los planes de estudio con una asignatura de religión en clave no confesional sin desterrar la asignatura confesional. Estas asignaturas no tienen que tener carácter alternativo, pueden ser complementarias. Son muchas las opciones que se abren en este sentido, pero la necesidad que plantea la OSCE hace que el estudio no confesional deba constituirse en obligatorio en tanto que el confesional debe, por imperativo legal, ser voluntario para los alumnos. Si se pueden cursar ambas, o no, será una cuestión de política educativa.

La LOMLOE habla de enseñanza confesional y no confesional de cultura de las religiones. Ese es el nombre elegido por la ley: «cultura de las religiones», sin embargo, no es el más usual. Historia de las Religiones es una de las denominaciones más habituales, aunque no la única. Como señala Díez de Velasco, desde otras disciplinas se utilizan nombres diferentes como Estudios Religiosos (Religious Studies), Ciencia de la Religión (Religionswissenschaft) o su pluralización en Ciencias de las Religiones o el más largo Estudio científico de la Religión, entre otros ${ }^{76}$. Se plantea,

75 Meseguer reflexiona sobre estas dificultades en: Silvia Meseguer Velasco. "Prevenir la radicalización en la escuela". Anuario de derecho eclesiástico del Estado 36 (2020): 397-420.

76 Francisco P. Díez de Velasco Abellán. "Enseñar religiones desde una óptica no confesional: reflexiones sobre (y más allá de) una alternativa a 'religión' en la escuela". Clio: History and History Teaching 22 (2001). http://clio.rediris.es/articulos/ religionestexto.htm 
por tanto, una disciplina en la que se emplean métodos filológicos, históricos y socioempíricos en su estudio del fenómeno religioso. Parte de estos estudios se ocupan de las religiones concretas, que son estudiadas generalmente desde la Historia de las Religiones y, por otra parte, desde las Ciencias sistemáticas de las Religiones, «que se ocupan del estudio comparado de las religiones o de aspectos concretos de ellas, así como de formular teorías generales acerca de las religiones. Ninguno de estos ámbitos se plantea su investigación desde la perspectiva del dogma de la religión o de las religiones estudiadas $»^{77}$. Alejada de una perspectiva teológica o apologética, puede enfocarse desde una óptica universal que permita el repaso de las religiones del mundo, con una vocación interdisciplinar, «su apertura a la alteridad de otras creencias y otras culturas, la inserción en el sistema educativo español de estos modos de encarar el estudio del fenómeno religioso puede resultar muy adecuada». El contenido específico de la materia deberá responder a estas premisas. No puede ofrecerse esta asignatura desde lo singular, no debe mezclarse con la perspectiva confesional. Se trata de elaborar una verdadera educación en la pluralidad, que plantea no pocos problemas teóricos a la hora de establecerse de un modo satisfactorio y contextualizado ${ }^{78}$. Sin embargo, no sería única. Un número nada desdeñable de países de nuestro entorno cuentan con una enseñanza de estas características ${ }^{79}$.

77 Peter Antes. "Las ciencias de las religiones como disciplina universitaria". Boletín de la Sociedad Española de Ciencias de Religiones 3 (1995): 26.

78 Díez de Velasco cita en su obra "La enseñanza de las religiones en la escuela en España: avatares del modelo de aula segregada”, los trabajos de Robert Jackson, Religious Education: An Interpreta-tive Approach (London: Hodder\&Stoughton, 1997), y Rethinking Religious Education and Plurality: Issues in Diversity and Pedagogy (London: Routledge-Falmer, 2004), o K. Engebretson et al., (eds.), International Handbook of Inter-religious Education (Dordrecht: Springer, 2010), entre otros. Resulta particularmente útil Robert Jackson. Señales - Políticas públicas y prácticas para la enseñanza de las religiones y las cosmovisiones no-religiosas en la educación intercultural. Estrasburgo: Consejo de Europa, 2015; Francisco P. Díez de Velasco. "La enseñanza de las religiones en la escuela en España: avatares del modelo de aula segregada”. En "Educación y religión católica en la Europa moderna y contemporánea". Historia y Memoria de la Educación, 4 (2016): 277-306.

79 José María Contreras Mazarío. "La enseñanza religiosa en derecho internacional y comparado". Bandue. Revista de la Sociedad Española de Ciencias de las Religiones 1 (2007): 47-82; Jean Paul Willaime. "Different Models for Religion and Education in Europe". En Religion and Education in Europe: Developments, Contents and Debates, editado por Robert Jackson et al., 57-66. Münster: Waxmann, 2005. 
El próximo reto de las autoridades académicas pasará por determinar el currículo a la luz de las Recomendaciones de la Haya en materia de la enseñanza de la religión ${ }^{80}$. La implantación de esta asignatura debe tener - a nuestro juicio- una finalidad concreta en el currículo. Creemos que el objetivo principal debe ser erradicar la idea de que la religión es un foco de conflicto en la escuela. Desde el conocimiento de la realidad española, pasando por el conocimiento histórico de la religiosidad, una aproximación a otras religiones presentes en nuestro país y el análisis de las más relevantes en el mundo permitiría al estudiante percibir la pluralidad de creencias como algo real. La materia que sugerimos no puede marginar el estudio de los derechos humanos y muy especialmente el de libertad religiosa. Conocer los modelos de Estado en función de lo religioso resulta imprescindible ya que pone de manifiesto las consecuencias de la intolerancia o prohibición en materia religiosa.

El modelo propuesto para una enseñanza no confesional, en un principio ajeno a las confesiones y a la experiencia de fe, podría verse beneficiado incluyendo ambas. Tomando prestada la idea que plantean Grimmit y Read, «learning from religion ${ }^{81}$ sería posible la colaboración de las entidades religiosas de tal manera que quede reflejada su perspectiva. En este sentido, ya que los líderes religiosos, las organizaciones confesionales y los grupos religiosos pueden desempeñar un papel decisivo de cohesión social promoviendo la comprensión y respeto mutuos.

Así la «cultura de las religiones» necesariamente debe construir un ambiente en el que han de confluir diferentes cosmovisiones en el marco de la comunidad educativa sobre la cual el profesor tiene el desafío de garantizar la inclusión y tolerancia en la aproximación respetuosa y empática hacia las diferentes alteridades de sus estudiantes ${ }^{82}$.

Hemos dejado claro que la normativa pactada con las confesiones respecto de los profesores de religión precisa de su intervención. No puede ocurrir lo mismo en este caso. Independiente de las colaboraciones

${ }_{80}$ https://www.osce.org/files/f/documents/7/8/32193.pdf, últ. 14 septiembre 2021. Enseñanza, últ. 17 septiembre 2021.

81 Michael Grimmit. What Can I Do In R.E? A Consideration of The Place Of Religion In The Twentieth-Century Curriculum With Suggestions For Practical Work In Schools. Great Wakering, Mayhew-Mccrimmon, 1973.

82 Tatiana Guerrero Díaz. "Educación valórica inclusiva y los desafíos de la educación religiosa para ser garante de tolerancia e inclusión social”. Horizonte de la Ciencia 10 (2020): 1. 
que se puedan realizar de modo testimonial y para contribuir a un conocimiento de las religiones desde la perspectiva confesional, ya hemos dicho que el carácter de esta materia es otro, y así debe ser la selección del profesorado. Díez de Velasco insiste en que la docencia en una asignatura con las características ya señaladas, la podrían encaminar tanto historiadores como filólogos, filósofos y en general otros educadores. Coincidimos con el autor en que resultaría necesaria una capacitación ya que posee una serie de intereses formativos, tanto en lo que respecta al comportamiento como al conocimiento ${ }^{83}$. Los requisitos para ser profesor de primaria y secundaria deben ser los exigibles a estos docentes, además de una formación específica en ciencias de las religiones. Por tanto, habrán de disponer de un grado de Magisterio en Educación Primaria o la diplomatura para Primaria y de un grado, licenciatura, ingeniería o arquitectura para Secundaria. Además de tener el Máster de Educación (o equivalente), la formación específica en religiones, algo que, sin duda, deberá implementarse en los programas universitarios y, en el caso del acceso a centros educativos públicos, habrán de superar el concurso-oposición correspondiente.

Queda por tratar un último asunto, el de la mera convivencia en las aulas. Vestimentas religiosas, uso de símbolos, alimentación, prácticas religiosas, etc. ${ }^{84}$. Todas ellas son, sin duda, cuestiones que los poderes pú-

83 Francisco P. Díez de Velasco Abellán. "Enseñar religiones desde una óptica no confesional...", cit.

${ }^{84}$ Las cuestiones son de plena actualidad y han sido apuntadas por la doctrina en distintos ámbitos: Isabel Cano Ruíz. "El uso del velo islámico en el ámbito educativo". En El velo islámico y los derechos fundamentales de la mujer, coordinado por Miguel Rodríguez Blanco, 91-124. Fundación Canis Majoris, 2020; Óscar Celador Angón. "Neutralidad de los poderes públicos y símbolos políticos". Revista General de Derecho Administrativo 53 (2020); Óscar Celador Angón. "El modelo de educación diferenciada en la reciente doctrina constitucional". Derechos y libertades: Revista de Filosofía del Derecho y derechos humanos 42 (2020): 27-60; Agustín Motilla de la Calle. "La enseñanza de la religión en los centros educativos". En Derecho de la libertad religiosa, coordinado por José María Porras Ramírez, 267-296. Madrid: Tecnos, 2021; María Cruz Llamazares Calzadilla. "Extranjería y derecho de libertad religiosa”. En Tratado de extranjería: aspectos civiles, penales, administrativos y sociales, coordinado por Alberto Palomar Olmeda y Pablo Benlloch Sanz, 1213-1235. Madrid: Aranzadi, 2020; María Cruz Llamazares Calzadilla. "Los símbolos religiosos como campo de pruebas de la libertad religiosa en Europa Occidental". Laicidad y libertades: escritos jurídicos 18 (2018): 229-258; Javier Martínez-Torrón y Santiago Cañamares Arribas (Eds.). Libertad religiosa, neutralidad del Estado 
blicos deberán afrontar siguiendo el mandato del 16.3. Su análisis precisa de otro estudio, quedo emplazada a ello.

\section{REFERENCIAS}

Antes, Peter. "Las ciencias de las religiones como disciplina universitaria". Boletín de la Sociedad Española de Ciencias de Religiones 3 (1995): 26.

Barrero Ortega. La libertad religiosa en España. Madrid: Centro de Estudios Políticos y Constitucionales, 2006.

Briones Martínez, Irene M. "Inmigración e interculturalidad". En Algunas cuestiones controvertidas del ejercicio del derecho fundamental de libertad religiosa en España, coordinado por Isidoro Martín Sánchez y Marcos González Sánchez, 361-390. Madrid: Fundación Universitaria Española, 2009.

Cano Ruíz, Isabel. "El uso del velo islámico en el ámbito educativo". En El velo islámico y los derechos fundamentales de la mujer, coordinado por Miguel Rodríguez Blanco, 91-124. Fundación Canis Majoris, 2020.

Cebriá García, María Dolores. "La enseñanza de la religión en las Comunidades Autónomas”. Derecho y Religión 14 (2019): 53-76.

Celador Angón, Óscar. "Neutralidad de los poderes públicos y símbolos políticos". Revista General de Derecho Administrativo 53 (2020).

Celador Angón, Óscar. "El modelo de educación diferenciada en la reciente doctrina constitucional". Derechos y libertades: Revista de Filosofía del Derecho y derechos humanos 42 (2020): 27-60.

Celador Angón, Óscar. "Libertad de conciencia, integración e inmigración. Lecciones desde el Reino Unido". Cuadernos electrónicos de filosofía del derecho 43 (2020). https://doi.org/10.7203/CEFD.43.17059

Ciáurriz Labiano, María José. "La Enseñanza Superior en el Acuerdo sobre Enseñanza y Asuntos Culturas: visión de conjunto". En Enseñanza superior y religión en el ordenamiento jurídico: actas del VII simposio internacional de derecho concordatario, Trujillo (Cáceres), 7-9 de octubre de 2015, editado por María Dolores Cebriá García, 57-82. Granada: Comares, 2016.

y educación: una perspectiva europea y latinoamericana. Cizur - Menor: Thomson Reuters Aranzadi, 2019. 
Ciáurriz Labiano, María José. "La vigente Ley Orgánica de Libertad Religiosa: Una gran novedad jurídica". En "40 aniversario de la Ley Orgánica de Libertad Religiosa”. Derecho y religión 15 (2020): 251-262.

Cubillas Recio, Mariano. "La enseñanza de la religión en el sistema español y su fundamentación en el derecho de los padres sobre la formación religiosa de sus hijos". Laicidad y Libertades. Escritos Jurídicos 2 (2002) 157-219.

Ciáurriz Labiano, María José. "La objeción de conciencia". En Derecho eclesiástico del Estado, coordinado por Gustavo Suárez Pertierra, 139168. Valencia: Tirant lo Blanch, 2016.

Contreras Mazarío, José María. "La enseñanza religiosa en derecho internacional y comparado". Bandue. Revista de la Sociedad Española de Ciencias de las Religiones 1 (2007): 47-82.

Díez de Velasco Abellán, Francisco P. "Enseñar religiones desde una óptica no confesional: reflexiones sobre (y más allá de) una alternativa a 'religión' en la escuela”. Clio: History and History Teaching 22 (2001). http://clio.rediris.es/articulos/religionestexto.htm

Díez de Velasco, Francisco P. "La enseñanza de las religiones en la escuela en España: avatares del modelo de aula segregada". En "Educación y religión católica en la Europa moderna y contemporánea". Historia y Memoria de la Educación 4 (2016): 277-306. https://doi.org/10.5944/ hme.4.2016.15484

Fanjul Suárez, Gonzalo. "Migraciones internacionales: las consecuencias de gobernar el siglo XXI con políticas del XIX. En ARI 56/2010 - 23/03/2010, Publicaciones del Real Instituto Elcano.

Fernández-Coronado González, Ana. "Libertad de enseñanza (Derecho Eclesiástico)”. En Enciclopedia Jurídica Básica III, 4034. Madrid, 1995. Ferrari, Silvio. "Introducción". En Derecho y Religión en Europa occidental, S. Ferrari y I. C. Ibán. Madrid: McGraw-Hill, 1998.

Gómez Sánchez, Yolanda, Teresa Freixes Sanjuán y Antonio Rovira Viñas (Dirs.). Constitucionalismo multinivel y relaciones entre Parlamentos: Parlamento europeo, Parlamentos nacionales y Parlamentos regionales con competencias legislativas. Madrid: Centro de Estudios Políticos y Constitucionales, 2013.

Grimmit, Michael. What Can I Do In R.E? A Consideration Of The Place Of Religion In The Twentieth-Century Curriculum With Suggestions For Practical Work In Schools. Great Wakering: Mayhew-Mccrimmon, 1973. 
Guerrero Díaz, Tatiana. "Educación valórica inclusiva y los desafíos de la educación religiosa para ser garante de tolerancia e inclusión social". Horizonte de la Ciencia 10 (2020): 1. https://doi.org/10.26490/uncp. horizonteciencia.2020.18.431

Ibán, Iván C. "Principios constitucionales del Derecho español". En Lecciones de Derecho eclesiástico, Iván C. Ibán y Luis Prieto Sanchís. Madrid: Tecnos, 1990, 130.

Ibán, Iván C. "Fuentes". En Derecho Eclesiástico, Iván C. Ibán, Luis Prieto Sanchís y Agustín Motilla de la Calle. Madrid 1997, 107.

Ibán, Iván C. Derecho eclesiástico. Madrid: Trotta, 2016.

Lema Tomé, Margarita. Laicidad e integración de los inmigrantes. Madrid: Marcial Pons, 2007.

Llamazares Calzadilla, María Cruz. "Extranjería y derecho de libertad religiosa”. En Tratado de extranjería: aspectos civiles, penales, administrativos y sociales, coordinado por Alberto Palomar Olmeda, 709-728. Madrid: Aranzadi, 2004.

Llamazares Calzadilla, María Cruz. "Los símbolos religiosos como campo de pruebas de la libertad religiosa en Europa Occidental". Laicidad y libertades: escritos jurídicos 18 (2018): 229-258.

Llamazares Calzadilla, María Cruz. "Extranjería y derecho de libertad religiosa”. En Tratado de extranjería: aspectos civiles, penales, administrativos y sociales, coordinado por Alberto Palomar Olmeda y Pablo Benlloch Sanz, 1213-1235. Madrid: Aranzadi, 2020.

Llamazares Fernández, Dionisio. Derecho de la libertad de conciencia II. Madrid: Civitas, 1999.

López Alarcón, Mariano. "Actitud del Estado ante el factor religioso". Anuario de Derecho Eclesiástico del Estado 5 (2008): 63-68.

López-Sidro López, Ángel. "Impacto de la doctrina del TEDH en la jurisprudencia española: la idoneidad y el vínculo de especial confianza del profesorado de religión". Anuario de derecho eclesiástico del Estado 34 (2018): 469-527.

Mantecón Sancho, Joaquín. "La enseñanza religiosa de las confesiones minoritarias en los Acuerdos de cooperación de 1992". Revista General de Derecho Canónico y Derecho Eclesiástico del Estado 44 (2017).

Martí, José María. "El nuevo perfil de la enseñanza religiosa en la reforma del sistema educativo no universitario". Anuario de Derecho Eclesiástico del Estado 8 (1992) 43-74. 
Martínez de Pisón, José. "Poderes públicos y religión. El difícil compromiso con la libertad de conciencia". REDUR 0 (2002): 94. https://doi. org/10.18172/redur.3813

Martínez-Torrón, Javier y Santiago Cañamares Arribas (Eds.). Libertad religiosa, neutralidad del Estado y educación: una perspectiva europea y latinoamericana. Cizur-Menor: Thomson Reuters Aranzadi, 2019.

Meseguer Velasco, Silvia. "Prevenir la radicalización en la escuela". Anuario de derecho eclesiástico del Estado 36 (2020): 397-420.

Moreno Botella, Gloria. "Profesores de religión: tres sentencias y un mismo fallo a favor de la autonomía confesional en el TEDH (un posible paradigma de solución para el caso Pavez)". Persona y derecho: Revista de fundamentación de las Instituciones Jurídicas y de Derechos Humanos 77 (2017): 271-308. https://doi.org/10.15581/011.77.271-308

Motilla de la Calle, Agustín. "La enseñanza de la religión en los centros educativos". En Derecho de la libertad religiosa, coordinado por José María Porras Ramírez, 267-296. Madrid: Tecnos, 2021.

Motilla de la Calle, Agustín. "La Ley Orgánica de Libertad Religiosa y las Comunidades Autónomas: la regulación autonómica de la libertad religiosa". Anuario de Derecho Eclesiástico del Estado 26 (2010): 359-404.

Muckel, Stefan. "El Estado y la Iglesia en Alemania". Revista catalana de dret públic 33 (2006): 267-293.

Odgers-Ortiz, Olga. "Migración, identidad y religión: aproximaciones al estudio del papel de la práctica religiosa en la redefinición identitaria de los migrantes mexicanos". Amerique Latine. Histoire \& Memoire 7 (2003). https://doi.org/10.4000/alhim.447

Otaduy Guerin, Jorge. "La idoneidad de los profesores de religión católica y su desarrollo jurisprudencial en España”. Estudios eclesiásticos: Revista de investigación e información teológica y canónica 88, n. 347 (2013): 849-871. https://revistas.comillas.edu/index.php/estudioseclesiasticos/ article/view/7417

Palomino Lozano, Rafael. "Profesores de religión en la escuela pública: autonomía de los grupos religiosos, neutralidad del estado y desconcierto final". Revista General de Derecho Canónico y Derecho Eclesiástico del Estado 43 (2017).

Polo Sabau, José Ramón. "La enseñanza de la religión en la escuela pública: fundamento constitucional y desarrollo normativo". Revista General de Derecho Administrativo 33 (2013). 
Polo Sabau, José Ramón. “A vueltas con la asignatura de religión tras la aprobación de la LOMLOE”. Diario La Ley 9763 (2021): 1.

Rodríguez Blanco, Miguel. "Breves consideraciones sobre la idoneidad de los profesores de religión en centros docentes públicos: a propósito de la Sentencia del Tribunal Superior de Justicia de Canarias, Sala de lo Social, de 17 de julio de 2007". Revista General de Derecho Canónico y Derecho Eclesiástico del Estado 16 (2008).

Rodríguez Moya, Almudena. "La gestión de la diversidad religiosa: una nueva realidad social vs. ¿una nueva realidad jurídica?”. En Religión, matrimonio y Derecho ante el siglo XXI: Estudios en homenaje al Profesor Rafael Navarro-Valls, coordinado por Javier Martínez Torrón, Silvia Meseguer Velasco y Rafael Palomino Lozano, vol. 1, 1445-1459. Madrid: Iustel, 2013.

Rodríguez Moya, Almudena. "Evolución y vigencia del principio de cooperación entre el Estado y las confesiones religiosas". En Derecho canónico en tiempos de cambio: actas de las XXX Jornadas de Actualidad Canónica, coord. por Jorge Otaduy Guerín, 109-124. Madrid: Dykinson, 2011.

Rodríguez Moya, Almudena. "Ayuntamientos y religión: el creciente papel de las entidades locales en la cooperación religiosa". Anuario De Derecho Eclesiástico del Estado 34 (2018): 331-356.

Santos Rego, Miguel Ángel. "La educación intercultural y el pluralismo religioso: Propuestas pedagógicas para el diálogo". En "El centro educativo ante la diversidad". Educación XXI: Revista de la Facultad de Educación 20 (2017): 17-35.

Souto Galván, Beatriz. "Multiculturalismo y pluralismo religioso". Derecho y opinión 8 (2000): 543-548.

Souviron Morenilla, José María. “Competencias propias y servicios mínimos obligatorios de los municipios en la reciente reforma del régimen local básico". Cuadernos de Derecho Local (QDL) 34 (2014): 80-97.

Suárez Pertierra, Gustavo. "La recuperación del modelo constitucional. La cuestión religiosa a los veinticinco años de la Constitución". Laicidad y libertades. Escritos jurídicos 2 (2002): 313-348.

Suárez Pertierra, Gustavo. "La enseñanza de la religión en el sistema educativo español". Laicidad y libertades. Escritos jurídicos 4 (2004): 225-248. 
Suárez Pertierra, Gustavo. "La enseñanza de la religión en el sistema educativo español". En Laicidad, educación y democracia, coordinado por Patricio de Blas Zabaleta, 143-160. Madrid: Biblioteca Nueva, 2005.

Suárez Pertierra, Gustavo. "Estado y religión: la calificación del modelo español". Revista catalana de dret public 33 (2006): 15-42.

Suárez Pertierra, Gustavo. "La libertad religiosa, ideológica y de culto". En Derecho eclesiástico del Estado, coordinado por Gustavo Suárez Pertierra, 119-138. Valencia: Tirant lo Blanch, 2016.

Willaime, Jean Paul. "Different Models for Religion and Education in Europe". En Religion and Education in Europe: Developments, Contents and Debates, editado por Robert Jackson, S. Miedema, W. Weisse y J-F. Willaime, 57-66. Münster: Waxmann, 2005. 